\title{
Aportes a la metalogénesis del basamento proterozoico superior-cámbrico de las Sierras Pampeanas Orientales: mineralogía, termometría e isótopos de azufre del skarn Malagueño (Cu-Fe \pm Zn), Sierra Chica, Córdoba, Argentina
}

\author{
María J. Espeche ${ }^{1,2}$, Raúl Lira ${ }^{1,2}$, Nicolás A. Viñas ${ }^{3}$
}

\author{
1 Laboratorio de Microscopía Óptica y Microtermometría-Museo de Mineralogía y Geología “Dr. Alfred W. Stelzner”, FCEFyN-UNC, \\ Av. Vélez Sarsfield 299, X5000JJC, Córdoba, Argentina. \\ maru-espeche@hotmail.com; raul.lira@unc.edu.ar \\ 2 Consejo Nacional de Investigaciones Científicas y Técnicas (CONICET). Av. Vélez Sarsfield 299, X5000JJC, Córdoba, Argentina. \\ ${ }^{3}$ Michelotti e Hijos S.R.L., Sargento Cabral 916, 5151, La Calera, Córdoba, Argentina. \\ n_vinas@michelotti.com.ar
}

RESUMEN. El avance de las tareas de explotación de mármoles en Malagueño, Sierra Chica de Córdoba, Argentina, ha puesto al descubierto en la Cantera Centro, vetas, vetillas y lentes de pirrotina >pirita@calcopirita >>esfalerita. Estos cuerpos mineralizados no superan los 0,3 m de espesor y los 2-3 m de largo continuo y, en conjunto, constituyen corridas intermitentes de hasta un centenar de metros. Los depósitos de sulfuros están asociados espacial y genéticamente a cuerpos de skarn. La secuencia metasedimentaria, que hospeda a los depósitos de skarn, constituida mayoritariamente por gneises, anfibolitas y mármoles, está intruida por diques metagábricos anfibólicos con diferenciaciones dioríticas, diques y plutones metatonalíticos y un metagranito álcali-feldespático; todo el complejo se halla metamorfizado en facies de anfibolita media a alta y fuertemente deformado como resultado del evento regional M2-D2/D3 que afectó al basamento neoproterozoico-cámbrico durante la orogenia Pampeana. A excepción de los gneises, todas las litologías registran evidencias de skarnificación diferencial, preferentemente desarrollada en mármoles, anfibolitas y metagranito, y en menor grado en los diques metagabro-dioríticos y metatonalíticos. Las rocas metasomáticas están representadas por un skarn granatífero $\left(\mathrm{Grs}_{27-48} \mathrm{Adr}_{22-34} \mathrm{Alm}_{15-27} \mathrm{Sps}_{9-21}\right)$ y piroxénico $\left(\mathrm{Hd}_{40-61} \mathrm{Di}_{35-54} \mathrm{Jo}_{4,7-6,4}\right)$, formado a partir del reemplazo de un metagranito; un skarn esencialmente piroxénico $\left(\mathrm{Hd}_{42-63} \mathrm{Di}_{32-50} \mathrm{JO}_{3-5}\right)$ desarrollado a partir de anfibolitas y un skarn formado a partir de un mármol cálcico y constituido principalmente por granate ( $\left.\operatorname{Adr}_{54-71} \operatorname{Grs}_{22-40} \mathrm{Alm}_{4-7} \mathrm{Sps}_{1-2}\right) \pm$ wollastonita. Los diques evidencian pobre reemplazo metasomático y carecen de sulfuros de origen metasomático-hidrotermal. La asociación retrogradante se compone de hastingsita, ferroactinolita, epidoto, clinozoisita, sericita, plagioclasa $\left(\mathrm{An}_{18}\right)$, chamosita y calcita. Los sulfuros están asociados a la paragénesis de relleno tardía del skarn, depositada según la sucesión temporal: calcita $\rightarrow$ clinocloro $\rightarrow$ cuarzo $\rightarrow$ pirita $\rightarrow$ pirrotina $\rightarrow$ calcopirita+esfalerita, como vetas y vetillas en el skarn de granate-piroxeno y como lentes de pirrotina maciza en el skarn de piroxeno. Los datos microtermométricos obtenidos a partir de inclusiones fluidas en calcita asociada a los sulfuros, la variación de la relación Fe/Mg en clinocloro y las relaciones de equilibrio de fases en pirrotina, sugieren que la paragénesis de relleno con sulfuros se formó entre $\sim 360$ y $250{ }^{\circ} \mathrm{C}$; cada rango termométrico guarda correspondencia con la secuencia temporal de precipitación de cada fase mineral, iniciada por descenso térmico a partir de un fluido en ebullición de moderada a alta salinidad ( 14,5 a 33,5\% en peso $\mathrm{NaCl}$ eq.). La elevada relación $\mathrm{Fe}^{+2} /\left(\mathrm{Fe}^{+2}+\mathrm{Fe}^{+3}\right)$ en granates y clinopiroxenos, los altos contenidos de granates subcálcicos (Alm+Sps), la presencia de sulfuros como cristales hijos y las altas relaciones $\mathrm{H}_{2} \mathrm{~S} / \mathrm{SO}_{4}{ }^{2-}$ del fluido vinculado a la precipitación de sulfuros, sugieren que el sistema evolucionó dominantemente bajo condiciones reductoras, lo que es también consistente con la presencia de pirrotina en la asociación de minerales sulfurados. La presencia de calcopirita y pirita diseminadas en metagabro-dioritas (Cu 300 ppm), así como los elevados contenidos de Cu en anfibolitas ( 900 ppm) permiten interpretar a estas litologías como potenciales fuentes de metales (Cu-Fe-Zn $\pm \mathrm{Ag}$ ). Los valores de $\delta^{34} \mathrm{~S}_{\Sigma f \text { luido }} \approx-4 \mathrm{a}+1,4 \%$ o calculados a partir del $\delta^{34} \mathrm{~S}$ de pirita, pirrotina y calcopirita entre 350 y $150{ }^{\circ} \mathrm{C}$, indican un origen magmático para el azufre, probablemente derivado de la lixiviación o desulfurización de los sulfuros primarios presentes en los intrusivos metagabro-dioríticos. Los metales y el azufre derivados de estos intrusivos y anfibolitas se habrían redistribuido en el skarn, movilizados por la acción de los fluidos metasomático-hidrotermales. Los skarns se habrían formado por infiltración de fluidos metasomáticos profundos e interacción fluido-roca que afectó las distintas litologías del basamento metamórfico-plutónico del Proterozoico superiorCámbrico. Los fluidos podrían provenir de intrusivos cámbricos no aflorantes o bien de la migmatización del basamento pampeano, canalizados a lo largo de contactos litológicos y fallas/fracturas. Las evidencias de yacencia, texturales y mineralógicas de la mineralización de sulfuros en Cantera Centro sugieren una edad cámbrica pos-deformacional asociada al orógeno Pampeano. 
ABSTRACT. Contributions to the metallogenesis of the Upper Proterozoic-Cambrian basement at the Eastern Sierras Pampeanas: Mineralogy, thermometry and sulfur isotopes in the Malagueño skarn (Cu-Fe $\pm \mathrm{Zn}$ ), Sierra Chica, Córdoba, Argentina. On-going mining operations in a marble quarry (Cantera Centro) from Malagueño, Sierra Chica de Córdoba, Argentina, have unearthed veins, veinlets and lenses of sulfides (pyrrhotite>pyrite $\cong$ chalcopyrite> >sphalerite). These veins and lenses are up to $0.3 \mathrm{~m}$ thick and 2-3 m long, although intermittently can extend about a hundred meters. They are associated with skarns. The metasedimentary host sequence, largely composed of gneisses, amphibolites and marbles, was intruded by amphibolic metagabbro and metadiorite dykes, metatonalite plutons and alkali-feldspar metagranites; the whole complex was metamorphosed into medium to high amphibolite facies and strongly deformed as a result of the a regional event M2-D2/D3 that affected the Neoproterozoic-Cambrian basement during the Pampean orogeny. Except for gneisses, all the other metamorphic lithologies register evidence of differential alteration into skarn, although the process was preferentially developed on marbles, amphibolites and metagranite, and to a lesser extent on mafic and mesosilicic dykes. The metasomatic rocks are characterized by a garnet $>>$ pyroxene skarn $\left(\mathrm{Grs}_{27-48} \mathrm{Adr}_{22-34} \mathrm{Alm}_{15-27} \mathrm{Sps}_{9-21}\right)$, formed after the replacement of the metagranite; a pyroxene-rich skarn $\left(\mathrm{Hd}_{42-63} \mathrm{Di}_{32-50} \mathrm{Jo}_{3-5}\right)$ developed after para-amphibolite, and a garnet $\left(\mathrm{Adr}_{54-71} \mathrm{Grs}_{22-40} \mathrm{Alm}_{4-7} \mathrm{Sps}_{1-2}\right)$ ( \pm wollastonite) skarn that replaced a calcic marble. The dykes show poor metasomatic replacement and lack sulfides of metasomatic-hydrothermal origin. Retrograde mineral associations include hastingsite, ferroactinolite, epidote, clinozoisite, sericite, plagioclase $\left(\mathrm{An}_{18}\right)$, chamosite and calcite. The sulfide mineralization is paragenetically associated with late-stage, infilling skarn-hydrothermal minerals that were sequentially deposited as: calcite $\rightarrow$ clinochlore $\rightarrow$ quartz $\rightarrow$ pyrite $\rightarrow$ pyrrhotite $\rightarrow$ chalcopyrite + sphalerite; these phases occur as veins and veinlets within the garnet-pyroxene skarn, and as massive pyrrhotite lenses in the piroxenerich skarn. Microthermometric data from fluid inclusions in sulfide related calcite, together with the geothermometric data from the Fe/Mg ratios in clinochlore and the phase equilibria data from intergrown high and low $\mathrm{T}^{\circ} \mathrm{C}$ pyrrhotite phases, all constrain the infilling gangue phases and sulfide crystallization temperature within the $\sim 360{ }^{\circ} \mathrm{C}$ to $250{ }^{\circ} \mathrm{C}$ range; the gradual thermal decrease is in agreement with the temporal depositional sequence of the infilling phases. Fluid inclusion petrographic data and salinity estimations suggest that sulfide precipitation was triggered by boiling, from a fluid of moderate to high salinity ( 14.5 to $33.5 \mathrm{wt} \%$ eq. $\mathrm{NaCl}$ ). Evidence that the fluid evolved under dominantly reducing conditions are the high $\mathrm{Fe}^{+2} /\left(\mathrm{Fe}^{+2}+\mathrm{Fe}^{+3}\right)$ ratios and molar proportions of subcalcic garnet (Alm+Sps) in garnet-pyroxene skarn, the presence of fluid inclusion sulfide daughter crystals in calcite, the high $\mathrm{H}_{2} \mathrm{~S}_{/} \mathrm{SO}_{4}{ }^{2-}$ ratios in the sulfide-bearing fluid and the presence of pyrrhotite among the sulfide phases. Disseminated primary chalcopyrite and pyrite in metagabbro-diorite dykes $(\mathrm{Cu} \sim 300 \mathrm{ppm})$ and the high contents of Cu in amphibolite ( 900 ppm) suggest that these protolithic lithologies were the probable sources of metals $\left(\mathrm{Cu}>>\mathrm{Zn} \pm \mathrm{Ag}\right.$ ). Values of $\delta^{34} \mathrm{~S}_{\Sigma \mathrm{fluid}}$ between $\approx-4$ to $+1.4 \%$ obtained from the fractionations factors of pyrite, pyrrhotite and chalcopyrite within the thermal range 350 $150{ }^{\circ} \mathrm{C}$, indicate a magmatic source for sulfur, likely provided by leaching or desulfidation of primary sulfides of the metagabbro-diorite dykes. Metals and sulfur supplied by these dykes and amphibolite would have been redistributed in the skarn after the circulation of the metasomatic-hydrothermal fluids. Skarn bodies would have formed by infiltration of deep metasomatic fluids and fluid-rock interaction which affected lithologies of the Upper Proterozoic-Cambrian metamorphic basement. Fluids could have derived from hidden Cambrian intrusives, or from the surrounding regional migmatization, channeled along lithological contacts and faults/fractures. Field setting, textural and mineralogical evidence of sulfide mineralization in the skarn assemblage of Cantera Centro, suggest a Cambrian age associated to the post-deformational stage of the Pampean Orogeny.

Keywords: Skarn, Sulfides, Pampean orogeny, Fluid inclusions, Sulfur isotopes, Sierra Chica, Córdoba.

\section{Introducción}

Desde principios del siglo XX y hasta la actualidad, la localidad de Malagueño, ubicada en el departamento Santa María, provincia de Córdoba (Fig. 1A), se ha caracterizado por la producción de cal a partir de la explotación de canteras de mármol; éstas han sido operadas desde 1980 por Cementos Minetti S.R.L. y a partir de 1998 por la empresa Holcim S.A., hasta la actualidad.

El yacimiento se ha explotado por medio de 3 canteras (Sur, Centro y Norte). A partir del año 2005 aparecieron las primeras manifestaciones de sulfuros y, en 2013, durante las tareas de explotación de los frentes 548 y 558 de la Cantera Centro (Fig. 1B), se pusieron al descubierto vetas, vetillas y cuerpos macizos de sulfuros (pirrotina-pirita-calcopirita->> esfalerita) menores de $0,3 \mathrm{~m}$ de espesor con longitudes máximas de un par de metros. Están hospedados en skarns, de 3 a 4 metros de espesor y hasta un par de decenas de $m$ de extensión continua, aunque su ocurrencia intermitente puede alcanzar el centenar de metros, concordantes a pseudoconcordantes con la foliación general del complejo metamórfico. También 

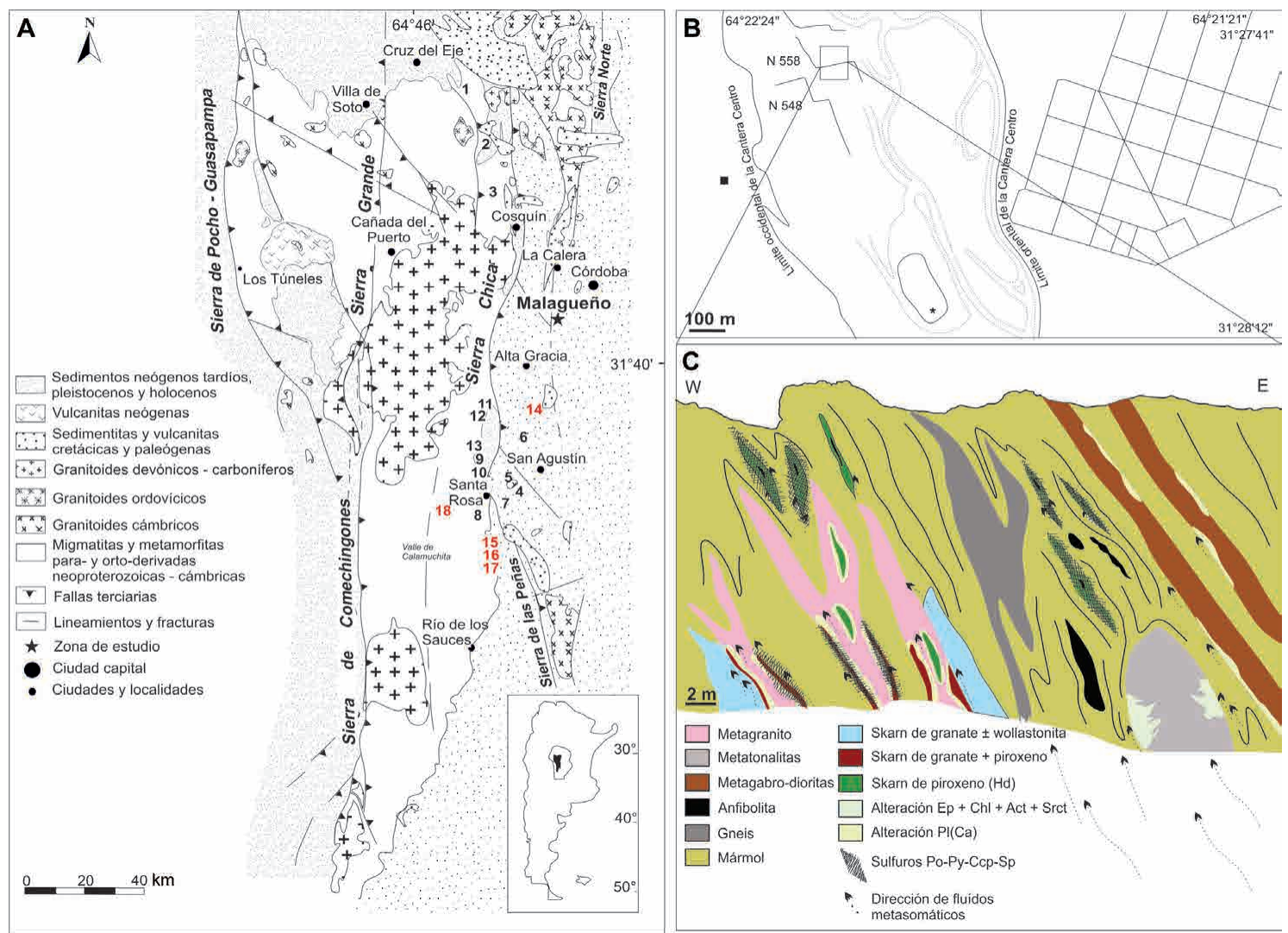

FIG. 1. A. Mapa geológico de la Sierra de Córdoba con la ubicación de las principales minas y manifestaciones de Cu-Fe (Zn-Au) en anfibolitas y Cu-Au en calizas, modificado y simplificado de Mutti y Di Marco (1999) y Martino y Guereschi (2014). Depósitos de $\mathrm{Cu}-\mathrm{Fe}$ (Zn-Au) en anfibolitas (en negro): distrito Punilla: 1: Cunuputo; 2: Cuchicorral; 3: Las Cuevas. Distrito Calamuchita: 4: Tío; 5: Tauro; 6: Tacurú; 7: Rita; 8: Estrella Gaucha. Distrito Santa Rosa: 9: Aída Rosa; 10: Aída; 11: Curuzú; 12: Cecilia; 13: 25 de Mayo. Depósitos de Cu-Au en calizas (en rojo): distrito Alta Gracia: 14: Fátima. Distrito Cañada de Álvarez: 15: Maero; 16: Oñate; 17: Achalay. Distrito Atos Pampa: 18: Cerro Azul. B. Diagrama esquemático en planta de la Cantera Centro de Malagueño; el recuadro negro señala la presencia de galena en venas de cuarzo en Cantera 10; la estrella indica el afloramiento del ortogneis tonalítico. C. Perfil oeste-este del frente 558 de la Cantera Centro representando las principales litologías.

se ha notado la presencia de galena en vetas de cuarzo emplazadas en gneises, a $\sim 400 \mathrm{~m}$ al suroeste de la zona de estudio, en la Cantera 10 (Fig. 1B; Viñas, 2017, comunicación personal).

Los antecedentes sobre la presencia de minerales de cobre en el área de estudio y zonas aledañas son escasos (Olsacher, 1938; Colombo et al., 2011, 2013). Olsacher (1938) menciona la existencia de pirrotina maciza asociada a cristales idiomorfos de turmalina, en el contacto de un granito con los mármoles de La Calera, $\sim 11 \mathrm{~km}$ al norte de la zona de estudio; sin embargo, algunas de las muestras referidas por Olsacher (1938) preservadas en la colección del Museo de Mineralogía y Geología "Dr. Alfred W. Stelzner” de la Universidad Nacional de Córdoba (ejemplares No. 110 y 1.566) corresponden a masas de pirrotina con inclusiones de cristales prismáticos oscuros de magnesio-hornblenda parcialmente cloritizados, sin turmalina. Colombo et al. (2011, 2013) describen la yacencia de minerales de cobre en canteras de mármol (dioptasa, plancheíta, crisocola, anilita, tenorita, covellita, spionkopita, malaquita y brochantita), ubicadas $\sim 4 \mathrm{~km}$ al norte de la localidad de La Calera y en el extremo sur de la Cantera Centro de Malagueño (kinoíta y tenorita).

Mutti y Di Marco (1999) realizaron una recopilación de información sobre yacimientos de $\mathrm{Cu}-\mathrm{Fe}$ ( $\mathrm{Zn}-\mathrm{Au})$ alojados en anfibolitas y de manifestaciones de $\mathrm{Cu}(\mathrm{Au})$ en mármoles localizados en las Sierras de Córdoba. Los primeros se distribuyen en los distritos mineros 
Punilla, Calamuchita y Santa María, en tanto los segundos lo hacen en los distritos mineros Cañada de Álvarez, Alta Gracia y Atos Pampa (Fig. 1A). Los depósitos de $\mathrm{Cu}-\mathrm{Fe}$ (Zn-Au) en anfibolitas se distribuyen a lo largo de las estribaciones de la Sierra Chica de Córdoba. De los depósitos de $\mathrm{Cu}(\mathrm{Au})$ en mármoles, la única mina ubicada en la vertiente oriental de la Sierra Chica es Fátima (Dawson, 1965ำ); las restantes manifestaciones se ubican en el valle de Calamuchita (Fig. 1A). La génesis de algunos de estos depósitos ha sido estudiada por Angelelli (1984), quien asigna a los depósitos del distrito Punilla y Calamuchita un carácter hidrotermal relacionado a intrusiones graníticas, mientras que Mutti y Di Marco (1999) atribuyen la génesis de los depósitos de los distritos Santa María y Calamuchita a un sistema hidrotermal submarino en rocas basálticas, vinculadas a un sistema de rifting de retroarco, activo durante el Neoproterozoico. El origen de bandas y crenulaciones concordantes de sulfuros (calcosina, calcopirita, neodigenita y otros) y fases secundarias de cobre en mármoles dolomíticos calcíticos en las minas del distrito Cañada de Álvarez, fue atribuido a procesos sinsedimentarios marinos vinculados a concentraciones algales (Brodtkorb et al., 1981, 2014).

Las manifestaciones de skarn desprovistas de minerales sulfurados son comunes en la provincia de Córdoba; estos skarns se presentan en los contactos de mármoles y anfibolitas del basamento neoproterozoico-cámbrico, con intrusivos de edades ordovícica y devónica. Los skarns de mayor desarrollo volumétrico presentes en las Sierras de Córdoba, son los vinculados a cuerpos pegmatíticos de la clase elementos raros (familia NYF o Híbrida) enriquecidos en Be-P-F-Nb-Ta-U-Li (Valdez, 1984; Franchini et al. 1998a, b, 1999; Galliski y Sfragulla, 2014; Lira y Sfragulla, 2014). Estos skarns están vinculados al magmatismo devónico-carbonífero anorogénico de Achala, enriquecido en F (Lira y Kirschbaum, 1990; Demange et al. 1996; Dorais et al., 1997; Dahlquist et al., 2013). Los skarns vinculados al magmatismo Achaliano presentan una mineralogía anómalamente rica en F que permite distinguirlos del resto de los skarns vinculados a intrusivos más antiguos como, por ejemplo, los estudiados por Gordillo (1965), Gordillo y Rossi (1968) y Lira y Gay (1999). El único caso publicado de un skarn vinculado temporalmente a intrusivos tardío-pampeanos, corresponde a un skarn cálcico de la Sierra Norte de Córdoba (Caspi Cuchuna), formado entre un lamprófiro spessartítico postcolisional y vetas epi-mesotermales preexistentes de calcita-clorita-cuarzo \pm sulfuros (O’Leary et al., 2002). D’Eramo et al. (2014) mencionan la formación de skarns epidóticos a partir de intrusivos trondhjemíticos de edad ordovícica al norte de la Sierra Chica de Córdoba.

El objetivo del presente trabajo es determinar las condiciones de formación del depósito tipo skarn de $\mathrm{Cu}-\mathrm{Fe} \pm \mathrm{Zn}$ presente en Malagueño. Para ello se estudió la mineralogía de los cuerpos de skarn, la composición química de las principales fases minerales, la geoquímica de algunos elementos traza de los protolitos y rocas adyacentes, la composición isotópica del azufre de las especies sulfuradas y la microtermometría de inclusiones fluidas en ganga de calcita asociada a los sulfuros.

\section{Metodología analítica}

Los análisis cuantitativos de minerales (modo WDS) y las imágenes de electrones retrodispersados (BSE) se realizaron con una microsonda electrónica JEOL JXA 8230 localizada en el Laboratorio de Microscopía Electrónica y Análisis por Rayos X, Facultad de Matemática, Astronomía y Física de la Universidad Nacional de Córdoba, Argentina, bajo las siguientes condiciones operativas: haz de electrones de $10 \mu \mathrm{m}$ de diámetro, corriente de haz de $20 \mathrm{nA}$, potencial de $15 \mathrm{kV}, 10$ segundos de conteo en el pico y 5 segundos en el fondo. Para la identificación de cristales hijos en inclusiones fluidas y otras fases minoritarias se utilizó el espectroscopio de energía dispersiva (EDS) acoplado a la microsonda. Se utilizaron los siguientes estándares: albita (Na), anortita (Al), forsterita ( $\mathrm{Si}, \mathrm{Mg}$ ), ortoclasa (K), wollastonita (Ca), baritina (Ba), ilmenita (Ti, Fe), celestina ( $\mathrm{Sr}$ ), libethenita $(\mathrm{P})$, rodonita $(\mathrm{Mn})$, cromita $(\mathrm{Cr})$, niquelina (Ni), fluorita (F), esfalerita (Zn), sodalita (Cl). Para el cálculo del $\mathrm{Fe}^{+3}$ en minerales, se siguió a Droop (1987). Los análisis de roca total se realizaron en ActLabs (Ancaster, Ontario, Canadá); se aplicó la metodología ICP-MS (Inductively Coupled Plasma Mass Spectrometry) para la mayoría de los elementos y la técnica de INAA(Instrumental Neutron Activation

1 Dawson, L.A. 1965. Estudio preliminar sobre las manifestaciones de cobre “Fátima” en José de la Quintana, pedanía San Isidro, departamento Santa Rosa, provincia de Córdoba. Informe técnico (Inédito). Instituto Nacional de Geología Minera: 13 p. 
Analysis) para Au. Los límites de detección utilizados experimentalmente fueron 30 ppm: Zn; 20 ppm: Ni; 10 ppm: Cu; 5 ppm: Cr, Pb, V; 0,5 ppm: Ag; 2 ppb: $\mathrm{Au}$. Para el estudio microtermométrico de inclusiones fluidas se utilizó una platina de enfriamientocalentamiento FLUID INC ubicada en el Laboratorio de Microscopía Óptica y Microtermometría del Museo de Mineralogía y Geología "Dr. Alfred W. Stelzner”, Facultad de Ciencias Exactas, Físicas y Naturales de la Universidad Nacional de Córdoba, Argentina, que opera en el rango térmico de $-196^{\circ} \mathrm{C}$ a $+700{ }^{\circ} \mathrm{C}$, con una precisión $\pm 0,1^{\circ} \mathrm{C}$ entre $-56,6^{\circ} \mathrm{C}$ $\mathrm{y}+660,4^{\circ} \mathrm{C}$; el equipo fue calibrado con inclusiones fluidas sintéticas de $\mathrm{H}_{2} \mathrm{O}$ pura y $\mathrm{H}_{2} \mathrm{O}+\mathrm{CO}_{2}$ puro, provistas por Syn Flinc (Virginia, USA), en el tramo negativo a $-56,6{ }^{\circ} \mathrm{C}$ y en el positivo a $+374,1^{\circ} \mathrm{C}$, y con baño de hielo con $\mathrm{H}_{2} \mathrm{O}$ tridestilada a $0,0{ }^{\circ} \mathrm{C}$. El procesamiento de datos se realizó con el programa FLUIDS (Bakker, 2003), utilizando las ecuaciones de estado de Bodnar y Vityk (1994). Los análisis de isótopos de azufre $\left(\delta^{34} S \%\right.$ ) se realizaron en Iso-Analytical Limited, Cheshire, Reino Unido. Se utilizó la técnica EA-IRMS (Elemental AnalysisIsotope Ratio Mass Spectrometry); los estándares de referencia aplicados fueron IA-R061 (sulfato de bario, $\delta^{34} S_{\mathrm{V}-\mathrm{CDT}}=+20,33 \%$ ), IA-R025 (sulfato de bario, $\delta^{34} \mathrm{~S}_{\mathrm{V}-\mathrm{CDT}}=+8,53 \%$ ) e IA-R026 (sulfuro de plata, $\delta^{34} S_{\mathrm{V}-\mathrm{CDT}}=+3,96 \%$ ) y se normalizaron con el estándar de referencia V-CDT (Vienna Canyon Diablo Troilite). Para la identificación de algunas fases sulfuradas con fines geotermométricos, se efectuaron análisis de difracción de rayos $\mathrm{X}$ en el Instituto de Investigaciones en Físico-Química de Córdoba, Facultad de Ciencias Químicas de la Universidad Nacional de Córdoba; se operó con radiación $\mathrm{CuK} \alpha$ filtrada con $\mathrm{Ni}$, a un voltaje de $40 \mathrm{kV}$ y corriente de $40 \mathrm{~mA}$. Los diagramas de difracción de todos los minerales fueron corridos entre 5 y $80^{\circ}$ con un paso de $0,02^{\circ}$, un tiempo de conteo de 6,49 segundos por paso. Las abreviaturas de minerales fueron tomadas de Whitney y Evans (2010).

\section{Geología regional}

La región de estudio se ubica en la vertiente oriental de la Sierra Chica de Córdoba, provincia geológica de Sierras Pampeanas Orientales (Miró 1999 y referencias allí citadas). Las Sierras de Córdoba están constituidas por un basamento ígneo-metamórfico del Proterozoico superior-Cámbrico, que se interpreta como una cuenca sedimentaria de margen pasivo, ubicada en el borde occidental del cratón Río de la Plata, metamorfizada y polideformada durante los ciclos orogénicos Pampeano y Famatiniano (Pankhurst y Rapela, 1998). Afloramientos de numerosos cuerpos ígneos intrusivos, con edades comprendidas entre el Cámbrico y el Carbonífero, están presentes a lo largo de las estribaciones de la Sierra de Comechingones al sur, Sierra de Guasapampa y de Pocho, Sierra Chica, Sierra Grande, hasta la Sierra Norte (Cingolani y Varela, 1975; Gordillo y Lencinas, 1979; Rapela et al., 1990; Kraemer et al., 1995; Lira et al., 1997). Los protolitos de las rocas que componen el basamento metamórfico, corresponden a secuencias volcánicosedimentarias con calizas y dolomías intercaladas. Estas fueron afectadas por procesos metamórficos que comprenden facies de esquistos verdes a granulitas y, en algunos casos, anatexis. Estas rocas se disponen en fajas de rumbo $\mathrm{N} / \mathrm{NO}$ a lo largo de las estribaciones orientales y occidentales de la Sierra Chica, Grande y de Comechingones. También se vinculan a esta secuencia rocas máficas metamorfizadas de origen ígneo y sedimentario (Tibaldi et al., 2014), algunas de éstas vinculadas espacialmente a rocas ultramáficas metamorfizadas (Martino et al., 2010; Anzil et al., 2014), originariamente interpretadas como secuencias ofiolíticas (Escayola y Kraemer, 2003; Escayola et al., 2007).

Sobre el basamento ígneo-metamórfico del Proterozoico superior (Cámbrico), se disponen depósitos del Paleozoico superior (CarboníferoPérmico), que corresponden a secuencias sedimentarias continentales fluvio-lacustres, aflorantes en diversas regiones de las Sierras de Córdoba (Gordillo y Lencinas, 1979; Astini y Del Papa, 2014). Los depósitos del Mesozoico tienen su expresión a lo largo de la Sierra Chica de Córdoba, representados por rocas sedimentarias, volcánicas y volcaniclásticas, vinculadas a un ambiente de sin-rift, y coladas basálticas alcalinas extensionales de rift del Cretácico inferior (Astini y Oviedo, 2014; Lagorio et al., 2014). Durante el Neógeno (7,9- 4,7 Ma) se registra un evento volcánico calcoalcalino que responde a las manifestaciones más orientales del arco volcánico andino en la provincia (Kay y Gordillo, 1994; Arnosio et al., 2014). Los depósitos continentales neógenos y cenozoicos son de tipo aluvial, fluvial, eólico, lacustre y de llanura, y se distribuyen a lo largo de los valles interserranos de las Sierras de Córdoba (Astini et al., 2014). 
La tectónica compresiva andina del Terciario definió la configuración de las Sierras Pampeanas, provocando una reestructuración del basamento y ascenso tectónico que favoreció al ciclo erosivo modelando la topografía hasta su disposición actual.

\section{Geología del área de estudio}

El basamento proterozoico superior-cámbrico en la zona de estudio forma parte del Complejo Metamórfico Sierra Chica (Bonalumi et al., 1999) y está constituido por gneises biotíticos, equivalentes al denominado Gneis Sierra Chica (Bonalumi et al., 1999) o “Gneis Común” de Pastore (1932), mármoles puros e impuros y anfibolitas en menor grado. Los intrusivos ígneos metamorfizados que afloran en el área corresponden a diques de metagranitos álcalifeldespáticos, metatonalíticos y metagabro-dioríticos (Fig. 1C). También son frecuentes las vetas de cuarzo. Además de las litologías mencionadas anteriormente, que conforman los frentes de explotación 548 y 558 de la Cantera Centro, al sur de ésta aflora un plutón metatonalítico deformado y silicificado (Fig. 1B). Toda la secuencia se halla metamorfizada en facies de anfibolita media a alta y fuertemente deformada, con un estilo de doble ondulación y orientación predominantemente meridional (Martino, 1997²).

La estructura general es de una lente sigmoidal, de dimensiones kilométricas, producto de una intensa deformación postmetamórfica (D3), en un régimen no coaxial del tipo inverso dirigido hacia el oeste, en condiciones de alta temperatura (Martino y Guereschi, 2014). Esta lente esquistosa deformada se encuentra rodeada por migmatitas homogéneas y heterogéneas con granate, feldespato potásico y cordierita, producto de la fusión parcial en condiciones de alto grado definidas como M2 por Guereschi y Martino (2014).

\subsection{Gneises}

Son las rocas más abundantes en el área de estudio y corresponden a gneises biotíticos. Sin embargo, Martino (1997), Balbis (2006) ${ }^{3}$ y Argüello (2011) describen, además, para las zonas aledañas, las variedades de gneises sillimaníticos, miloníticos, milonítico tonalítico, granatíferos y migmatitas estromatíticas. Se presentan como grandes cuerpos inyectados y desmembrados dentro del mármol. Son de color oscuro, de grano grueso y están compuestos mayoritariamente por biotita, plagioclasa y cuarzo, definiendo una textura lepidogranoblástica, con cantidades muy subordinadas de apatita y titanita. Como alteración se observa a escala micrométrica epidotización parcial de la biotita.

\subsection{Mármoles}

La composición de los mármoles de Malagueño y Yocsina es cálcica con tenores de MgO-menores a $4 \%$ en peso (calcita magnesiana; Sfragulla et al., 1999). Como minerales accesorios se identificaron, en orden decreciente de abundancia, flogopita, clinopiroxeno, apatita y titanita. Estos no superan el 35\% modal en los mármoles más impuros. La textura general es granoblástica y presentan tonalidades grisáceas a rosadas y, a diferencia de éstos, los mármoles más puros son blancos. Algunos mármoles presentan tonalidades celestes y son portadores de wollastonita.

\subsection{Anfibolitas}

Las anfibolitas se hallan intercaladas concordantemente a modo de lentes deformadas y cuerpos con estructura tipo boudinage en el mármol. Son de color verde oscuro, de grano fino y están compuestas por anfíbol ( $65 \%)$, plagioclasa $(\sim 20 \%)$, biotita ( $15 \%)$ y trazas de calcopirita. La textura general es nematogranoblástica a nematolepidoblástica. La yacencia y mineralogía de estas rocas, a excepción de la presencia de calcopirita, son comparables a las descriptas por Tibaldi et al. (2014) para las paranfibolitas en facies de anfibolita media a alta aflorantes al sur de la Sierra Chica y Sierra de las Peñas y para las anfibolitas no diopsídicas descriptas por Gordillo y Lencinas (1979) aflorantes en distintos sectores de la Sierra Chica de Córdoba. La calcopirita, en granos anhedrales menores que $0,25 \mathrm{~mm}$, constituye menos del $0,5 \%$ en volumen del total de la roca. Como alteración de la calcopirita se reconocen calcosina y covellina.

\footnotetext{
2 Martino, R.D. 1997. Estructura General de los Yacimientos de Mármol de Yocsina y Malagueño, Sierra Chica de Córdoba; Argentina. Informe técnico (Inédito). CORCEMAR: 42 p.

3 Balbis, A. 2006. Mapeo geológico de detalle. Sector oeste de la Cantera Centro. Informe técnico (inédito). Cementos Minetti: 39 p.
} 


\subsection{Metagranito}

Se dispone como diques de aproximadamente 10 a $15 \mathrm{~m}$ de largo y 2 a $6 \mathrm{~m}$ de potencia, mayormente inyectados en los gneises biotíticos, concordantes, al menos según el rumbo, con el mármol y anfibolitas. Algunos de estos cuerpos presentan xenolitos gnéisicos y anfibolíticos (Fig. 2A). La textura general es granoblástica a porfiroblástica. Es de color rosado, inequigranular de grano grueso a muy grueso hasta pegmatítico, con feldespatos potásicos de hasta $6 \mathrm{~cm}$. Está compuesto por microclino con textura pertítica en flamas $\left(\mathrm{Or}_{95} \mathrm{Ab}_{5} ; \sim 80 \%\right) \mathrm{y}$ cuarzo ( 20\%); la plagioclasa solo está presente como exsoluciones pertíticas. Los valores modales permiten clasificarlo como granito álcali-feldespático (Streckeisen, 1976). Como mineral accesorio se reconoce circón.
Cristales de granate de hasta $3 \mathrm{~cm}$ de diámetro con bordes completamente reemplazados por epidoto (Fig. 2B) corresponden a fases secundarias de reemplazo. A escala microscópica también se observa oligoclasa - andesina ( $\mathrm{An}_{26-38}$; muestra No. 558-09a, Pl16, Pl17, Tabla 1) de distribución irregular entre los megacristales de microclino y cuarzo del granito. La plagioclasa se presenta en agregados de cristales pequeños $(0,1$ a $0,7 \mathrm{~mm})$ fuertemente alterados a arcillas y reemplazados diferencialmente por muscovita de grano fino (sericita), epidoto y calcita (Fig. 2C). También se observa oligoclasa intersticial $\left(\mathrm{An}_{18}\right.$; muestra No. 558-09a, Pl2 y Pl4, Tabla 1), de grano más fino, que reemplaza centrípetamente a los granos de plagioclasa más cálcica, epidoto y feldespato potásico del granito (Fig. 2D). Todos estos minerales de reemplazo representan la skarnificación parcial del intrusivo granítico álcali-feldespático.
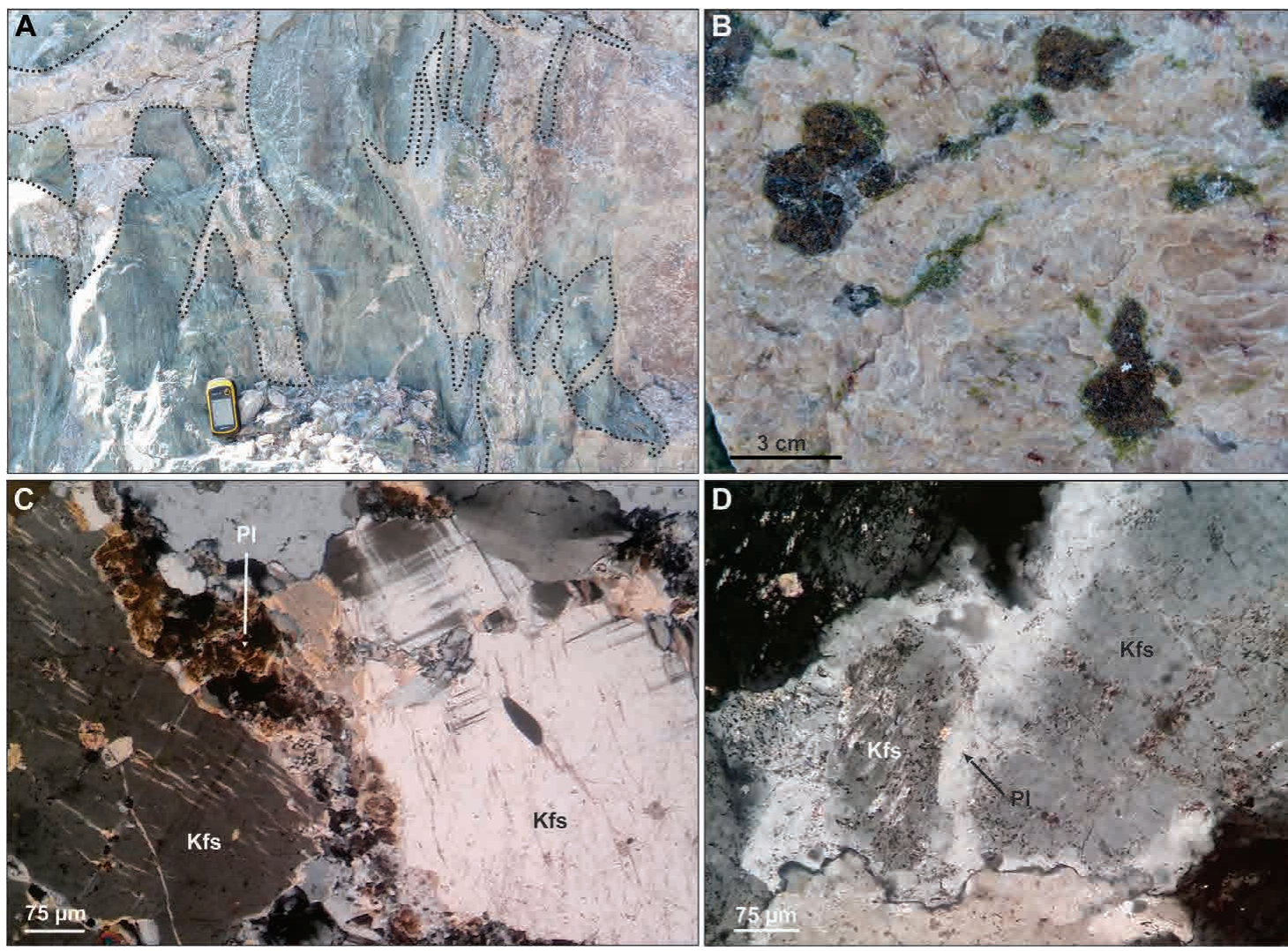

FIG. 2. A. Granito álcali-feldespático (color rosado) intruyendo a anfibolitas (color gris) en el frente 558 de la Cantera Centro. B. Cristales de granate con rebordes de epidoto de reemplazo (color oscuro) en el granito (zona de skarn granate-piroxeno). C. Agregados intergranulares de plagioclasa metasomática (oligoclasa-andesina, Pl) en el granito, cristalizada entre microclino (Kfs). D. Frente de reemplazo de oligoclasa (PI) a modo de rebordes sobre los granos de microclino (Kfs). 


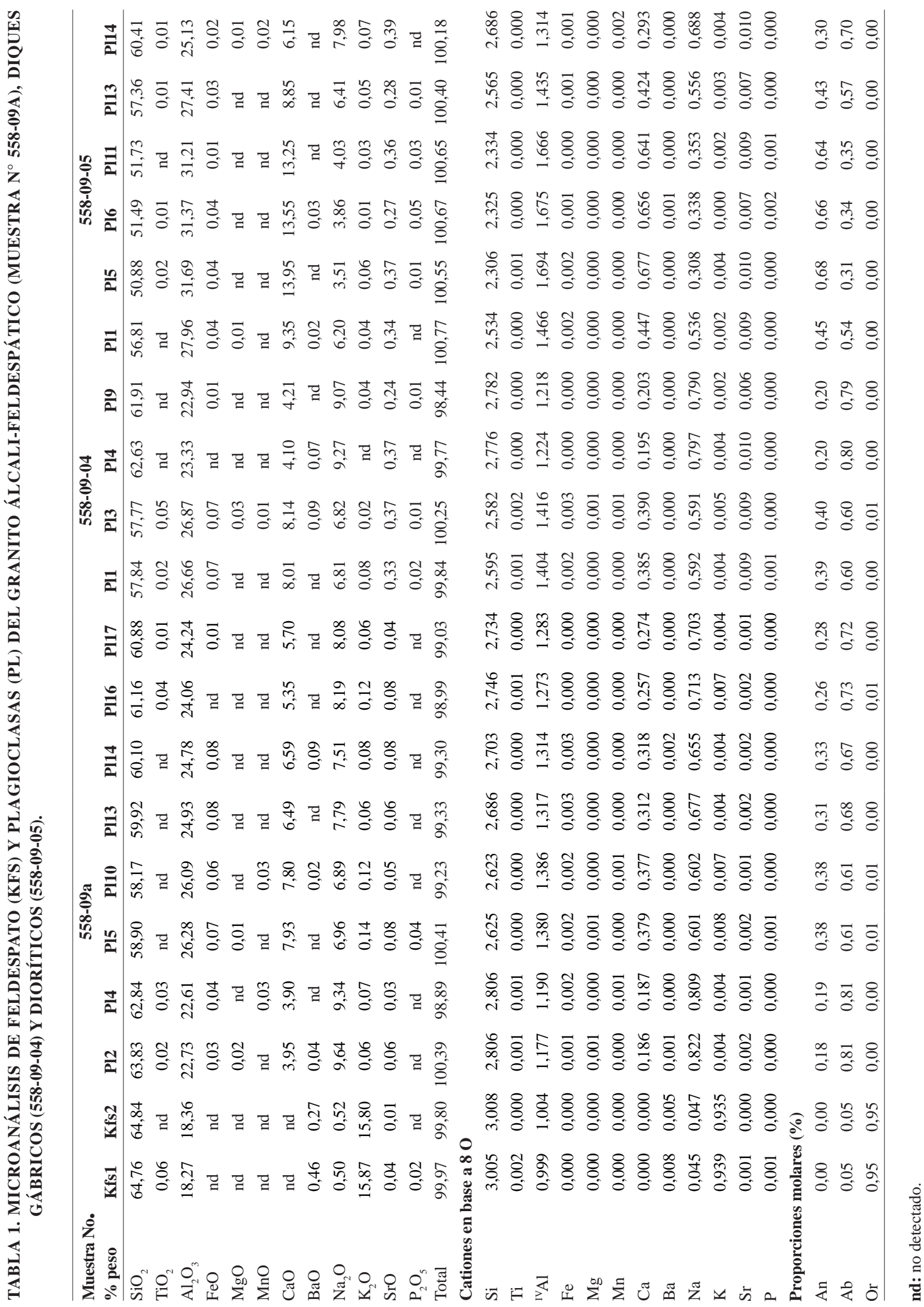




\subsection{Metagabro-dioritas anfibólicos}

Son diques de aproximadamente $2 \mathrm{~m}$ de espesor y varias decenas de metros de largo, de color oscuro, grano grueso y fuertemente deformados que se disponen concordantemente con la foliación de las rocas metamórficas encajonantes. Están constituidos mayoritariamente por ferroedenita ( $40 \%$; Tabla 2, acorde a la clasificación de Hawthorne et al., 2012), biotita ( 20\%), plagioclasa ( 30\%) y cuarzo recristalizado $(<10 \%)$. La textura general es nematoblástica y presenta una matriz granoblástica de grano fino con plagioclasa y escaso cuarzo. Como minerales subordinados ( $10 \%)$ se reconocen, calcopirita, pirita, magnetita, ilmenita, titanita y circón. La calcopirita se presenta como granos diseminados subhedrales de hasta $2 \mathrm{~mm}$ e inclusiones anhedrales en los granos de pirita. La pirita se halla como granos diseminados euhedrales a subhedrales, con tamaño entre 1 y 3 mm. La magnetita es anhedral a subhedral y presenta exsoluciones lamelares de ilmenita; algunos cristales presentan inclusiones de pirita euhedral aunque la mayoría de los cristales de magnetita se hallan formando rebordes alrededor de pirita definiendo una textura en rosario o cadena. El circón es un accesorio común, característica no frecuente en gabros y rocas máficas calcoalcalinas; se halla en agregados de cristales euhedrales a subhedrales de hasta 0,25 mm de largo. Como alteración se observa reemplazo parcial a total de calcopirita por covellina, débil oxidación de la magnetita y epidotización y sericitización de la plagioclasa.

Estos diques presentan diferenciaciones lentiformes de aspecto cumulático de hasta un par de decímetros de ancho y varios decímetros de largo (Fig. 3A). Están compuestos principalmente por fenocristales de plagioclasa zonada $\left(\sim 60 \%, \mathrm{An}_{43-68}\right)$ de hasta $3 \mathrm{~cm}$ de largo en una matriz granolepidoblástica de grano fino de plagioclasa, cuarzo y biotita. Las fases accesorias están representadas por circón, pirita, calcopirita, ilmenita, magnetita y escasa titanita. Como alteración presenta moderada epidotización y sericitización de la plagioclasa y cloritización de biotita.

La relación $\mathrm{Fe} /(\mathrm{Fe}+\mathrm{Mg})$ de las biotitas en ambas rocas indica valores comprendidos entre 0,42 y 0,50 (Tabla 3). Los análisis de la plagioclasa de estos diques muestran una relación $\mathrm{Na} / \mathrm{Ca}$ que permite definirlas como labradorita con tendencia a andesina hacia los bordes de los granos. Algunos núcleos de plagioclasas tienen proporciones molares de An $\left(\mathrm{An}_{49,5-64,5}\right.$, Tabla 1) que caracterizan a gabros. Con esta plagioclasa magmática coexiste oligoclasa que conforma un mosaico intergranular, semejante textural y composicionalmente a la oligoclasa observada en el granito álcali-feldespático (muestra No. 558-09a, $\mathrm{Pl} 2$ y Pl4, Tabla 1). La oligoclasa se presenta como una fina matriz envolvente y penetrativa sobre los cristales mayores de plagioclasa magmática, a modo de rebordes o como parches irregulares de reemplazo (Fig. 3B).

\subsection{Metatonalitas}

Se presentan como pequeños plutones y diques pseudoconcordantes en el mármol (Fig. 3C). Son rocas compuestas por plagioclasa ( $60-65 \%)$, cuarzo ( $\sim 25-30 \%$ ) y biotita (<15\%) que presenta alteración a clorita+epidoto. Son de color gris oscuro y grano fino ( 2 mm). La textura general es granoblástica sobrepuesta a una textura magmática equigranular relicta. Ambas texturas han sido obliteradas por minerales de alteración (Fig. 3D); la plagioclasa con indicios de zonación composicional se encuentra fuertemente reemplazada por muscovita (sericita) y cantidades subordinadas de calcita y la biotita ha sido totalmente reemplazada por clorita+epidoto. Escasos cristales de apatita de hasta $2 \mathrm{~mm}$ de largo se encuentran inmersos en las zonas más alteradas. $\mathrm{Al}$ sur de la Cantera Centro (Fig. 1B) aflora un cuerpo metatonalítico fuertemente deformado y alterado con evidencias de silicificación. Presenta una textura granoblástica foliada sobrepuesta a la textura ígnea granular. La matriz es equigranular, silícea con superficies de flujo que evidencian intensa deformación. El bandeado gnéisico muy marcado con melanosomas ricos en biotita y leucosomas de cuarzo-plagioclasa, permiten definir a esta roca como un ortogneis tonalítico. Como alteración se observa reemplazo de biotita por clorita y de plagioclasa por muscovita (sericita) y epidoto.

\subsection{Skarns}

Los cuerpos de skarn afloran en el contacto entre las distintas litologías como frentes de reemplazo desde algunos centímetros hasta aproximadamente un metro de espesor en una extensión continua de un par de decenas de metros, aunque de manera intermitente puede extenderse hasta un centenar de 
TABLE 2. MICROANÁLISIS DE ANFÍBOLES EN DIQUES GÁBRICOS (MUESTRA No. 558-09-04) Y SKARN DE PIROXENO (MG-M1 Y MG-M2A).

\begin{tabular}{|c|c|c|c|c|c|c|c|c|c|c|c|c|c|c|c|c|}
\hline \multirow{2}{*}{$\begin{array}{c}\text { MuestraNo. } \\
\% \text { peso }\end{array}$} & \multicolumn{6}{|c|}{ 558-09-04 } & \multicolumn{5}{|c|}{ MG-M1 } & \multicolumn{5}{|c|}{ MG-M2a } \\
\hline & Inf2 & nf3 & Anf4 & Anf5 & Anf7 & Anf10 & Anf6 & Inf7 & Anf10 & Anf11 & Anf12 & Anf1 & Anf2 & Anf4 & Anf5 & Anf6 \\
\hline $\mathrm{iO}_{2}$ & 42,08 & 33 & 42,45 & 2,54 & 2,14 & 73 & 82 & 8,21 & 38,12 & 38,56 & 38,32 & 40,03 & 49,60 & 0,28 & 49,18 & 48,20 \\
\hline $\mathrm{iO}_{2}$ & 1,04 & 0,98 & 0,86 & 0,55 & 0,55 & 0,72 & 0,39 & 0,48 & 0,41 & 0,42 & 0,45 & 0,13 & 0,04 & 0,23 & 0,03 & 0,01 \\
\hline $\mathrm{l}_{2} \mathrm{O}_{3}$ & 13,29 & 13,21 & 12,64 & 12,72 & 13,38 & 12,22 & 11,31 & 11,30 & 11,50 & 11,32 & 11,53 & 9,90 & 2,88 & 9,94 & 3,15 & 3,82 \\
\hline $\mathrm{e}_{2} \mathrm{O}_{3}$ & 5,87 & 5,02 & 4,67 & 5,02 & 5,80 & 3,88 & 17,60 & 17,96 & 17,82 & 17,38 & 17,51 & 12,73 & nd & 13,06 & nd & 1,07 \\
\hline $\mathrm{eO}$ & 11,86 & 12,58 & 13,57 & 13,86 & 13,68 & 15,63 & 9,99 & 9,20 & 9,92 & 9,83 & 10,04 & 14,54 & 21,84 & 14,59 & 21,56 & 22,11 \\
\hline gO & 8,87 & 8,87 & 8,87 & 8,45 & 8,08 & & 4,80 & 4,97 & 4,78 & 5,04 & &, 59 &, 57 &, 68 &, 93 & 8,05 \\
\hline $\mathrm{nO}$ & 0,20 & 0,23 & 0,25 & 0,22 &, 31 & 0,21 & 0,88 & 0,90 & 0,92 & 0,88 & 0,90 & 0,81 & 1,01 &, 94 & 1,16 & 1,08 \\
\hline $\mathrm{aO}$ & 11,67 & 11,63 & 11,79 & 11,61 & 1,64 & 86 & 1,50 & 11,57 & 11,40 & 11,43 & 11,29 & 1,26 & 1,83 & 11,29 & 11,94 & 11,76 \\
\hline 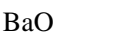 & 0,07 & 0,02 & 0,10 & 0,05 & 13 & ,03 & nd & nd & nd & nd & 0,11 & 0,02 & 0,06 & 0,16 & ,15 & nd \\
\hline 2 & 1,00 & 1,73 & 1,45 & ה כט, & 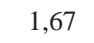 & ה כט, & 1,66 & 1,64 & 1,63 & 1,02 & (1, & סט, & 0,72 & $1,0 J$ & 0,74 & 0,93 \\
\hline${ }_{2} \mathrm{O}$ & nd & nd & nd & nd & nd & nd & 1,72 & 1,81 & 1,69 & 1,73 & 1,76 & 0,98 & 0,13 & ,91 & ),11 & 0,22 \\
\hline nO & nd & nd & 0,09 & nd & 0,04 & nd & nd & 0,02 & 0,07 & 0,11 & 0,08 & 0,09 & 0,06 & 0,02 & 0,06 & 0,06 \\
\hline & 0,06 & 0,05 & 0,06 & 0,04 & 0,07 & 0,05 & 0,30 & 0,30 & 0,29 & 0,23 & 0,27 & ,06 & nd & 0,06 & nd & nd \\
\hline l- & 0,13 & nd & 0,10 & nd & nd & 0,08 & 0,19 & 0,39 & 12 & 0,26 & ,14 &, 11 & 0,04 & nd & nd & nd \\
\hline otal & 96,96 & 96,66 & 96,90 & 96,65 & 96,92 & ,92 & 98,15 & 98,76 & 98,67 & 98,81 & 98,89 & 96,83 & 96,79 & 97,78 & 97,01 & 97,32 \\
\hline$=\mathrm{F}$ & 0,01 & 0,01 & 0,01 & 0,01 & 0,02 & 0,01 & 0,09 & 0,09 & 0,08 & 0,07 & 0,08 & 0,02 & 0,00 & 0,02 & 0,00 & 0,00 \\
\hline$=\mathrm{Cl}$ & 05 & nd & 0,04 & nd & d & 04 & 0,10 & 0,21 & 0,07 & 4 & 7 & 6 & 2 & 0 & 0 & 0 \\
\hline${ }_{2} \mathrm{O}$ & 72 & 1,84 & 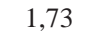 & 1,84 & 1 & & 1,59 & 1,51 & 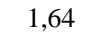 & 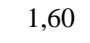 & 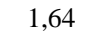 & 70 & & & 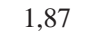 & 36 \\
\hline Total & 98,68 & 98,50 & 98,63 & 98,49 & & 30,01 & 99,60 & 100,03 & 100 & 100 & 100,42 & 98,47 & 98,62 & 99,54 & 98,88 & 99,18 \\
\hline \multicolumn{17}{|c|}{ Cationes en base a $24(\mathrm{O}, \mathrm{OH}, \mathrm{F}, \mathrm{Cl})$} \\
\hline Si & 6,580 & 6,628 & 6,669 & 6,697 & 6,605 & 6 , & 6,132 & 6,1 & 6 , & 6 & (1) & Do & 98 & 45 & ,892 & 7,739 \\
\hline$[1$ & 0,122 & 0,116 & 0,102 & 0,065 & 0,065 & 0,085 & 0,047 & 0,059 & 0,050 & 0,050 & 0,054 & 0,016 & 0,005 & 0,028 & 0,003 & 0,001 \\
\hline $\mathrm{Al}$ & 1,299 & 1,256 & 1,229 & 1,239 & 1,329 & 1,159 & 1,820 & 1,777 & 1,800 & 1,746 & 1,778 & 1,416 & 0,000 & 1,427 & 0,105 & 0,260 \\
\hline $\mathrm{Al}$ & 0,000 & 0,000 & 0,000 & 0,000 & 0,000 & 0,000 & 0,341 & 0,372 & 20,387 & 7 0,401 & L,409 & 0,498 & $3 \quad 0,547$ & 0,477 & 0,491 & 0,463 \\
\hline+3 & 0,700 & 0,599 & 0,559 & 0,603 & 0,694 & 0,466 & 2,259 & 2,290 & 2,271 & 2,206 & 2,2 & 1,627 & $7 \quad 0,000$ & 53 & 0,000 & 0,130 \\
\hline 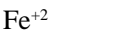 & 571 & 1,668 & 1,803 & 1,848 & 1,820 & 2,086 & 1,425 & 1,303 & 3,4 & 1,3 & 1,417 & 72, & $4 \quad 2,5$ & 2,053 & 2,893 & 2,977 \\
\hline Io & 2,068 & 2,071 & 2,078 & 1,983 & 1,888 & 1,912 & 1,160 & 1,1 & 1,150 & & & & $3 \quad 2,060$ & & 2,136 & 1,927 \\
\hline 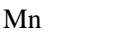 & 0,027 & 0,031 & 0,033 & 0,030 & 0,017 & 0,005 & 0,1 & 0,1 & 0,1 & 0,1 & & 0,113 & 0,1 & & 0,158 & 0,147 \\
\hline a & 1,955 & 1,951 & 1,985 & 1,958 & 1,955 & 2,009 & 1,998 & 2,000 & 1,971 & 1,970 & 1,947 & 1,979 & $\quad 2,044$ & 1,966 & 2,053 & 2,023 \\
\hline Ba & 0,004 & 0,001 & 0,006 & 0,003 & 0,008 & 0,002 & 0,000 & 0,000 & 0,000 & 0,000 & 0,007 & 0,001 & L,004 & 0,010 & 0,009 & 0,000 \\
\hline $\mathrm{Na}$ & 0,555 & 0,525 & 0,442 & 0,485 & 0,508 & 0,426 & 0,522 & 0,513 & 0,510 & 0,505 & 0,493 & 0,503 & 3 0,225 & 0,514 & 0,231 & 0,290 \\
\hline 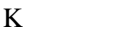 & 0,000 & 0,000 & 0,000 & 0,000 & 0,000 & 0,000 & 0,356 & 0,373 & 3,348 & 0,355 & 0,361 & 0,206 & 0,026 & 0,190 & 0,022 & 0,044 \\
\hline Zn & 0,000 & 0,000 & 0,011 & 0,000 & 0,005 & 0,000 & 0,000 & 0,002 & 2. 0,008 & 3 0,014 & 0,010 & 0,011 & 0,008 & 0,002 & 0,008 & 0,007 \\
\hline $\mathrm{Mg} /$ & ,568 & 0,554 & 0,535 & 0,518 & 509 & 478 & 0,449 & 0,478 & 0,450 & 466 & 0,454 & 0,352 & 2. 0,412 & 0,356 & 0,425 & 393 \\
\hline
\end{tabular}

nd: no detectado. $\mathrm{H}_{2} \mathrm{O}$ calculada. El FeO y $\mathrm{Fe}_{2} \mathrm{O}_{3}$ fue calculado siguiendo a Droop (1987).

metros, concordante a pseudoconcordante con la foliación general de las metamorfitas (Fig. 1C). De acuerdo a su composición se reconocen tres tipos de skarns: 1) Skarn de granate-piroxeno, 2) Skarn de piroxeno y 3) Skarn de granate \pm wollastonita (Fig. 4A, B, C, D). La mineralogía de cada uno está íntimamente vinculada a la composición del protolito reemplazado. Todas estas rocas han sido afectadas, en mayor o menor grado, por alteración retrógrada representada por la asociación epidoto ( \pm clinozoisita)-hastingsita-ferroactinolita-chamosita \pm sericita \pm plagioclasa $\left(\mathrm{An}_{18}\right) \pm$ calcita (Fig. 4E), 

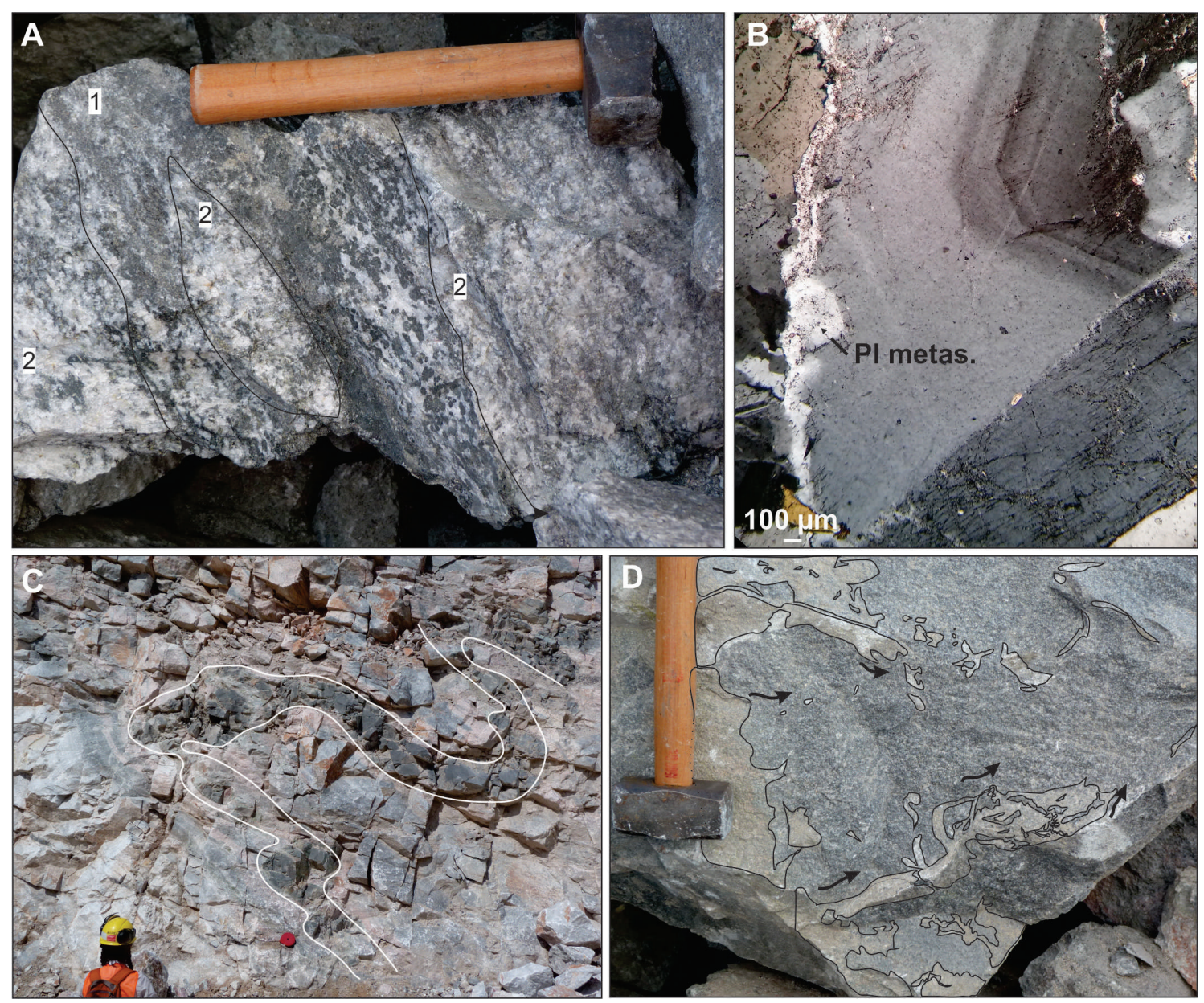

FIG. 3. A. Bloque de dique metagábrico (señalado con el No. 1; muestra No. 558-09-04) con diferenciados dioríticos porfíricos (señalado con el No. 2; muestra No. 558-09-05). B. Cristal de plagioclasa en dique gábrico con reborde de alteración metasomática de oligoclasa (Pl metas). C. Dique tonalítico plegado concordante con la roca de caja; frente de explotación 548, vista al este. D. Bloque de tonalita exhibiendo alteración metasomática constituida por epidoto-anfíbol-clorita-sericita de grano fino. Las flechas muestras el frente de alteración metasomático.

aunque esta asociación es más penetrativa en el skarn de granate-piroxeno. Finalmente se distingue la asociación calcita-clinocloro-cuarzo intercrecida con sulfuros (pirita-pirrotina-calcopirita-esfalerita), que caracteriza a la etapa tardía de relleno de skarn a modo de vetillas (Fig. 4F, G) y cuerpos macizos. A continuación se describen los distintos skarns.

\subsubsection{Skarn de granate-piroxeno}

Se halla reemplazando parcialmente al granito álcali-feldespático en no más de un metro de espesor. La asociación progradante está compuesta por granate y piroxeno ( \pm plagioclasa). No se observa zonación a ninguna escala a lo largo del skarn. Sobrepuesta a la asociación progradante se desarrolla la asociación retrógrada compuesta por actinolita, epidoto ( \pm clinozoisita), muscovita de grano fino (sericita), plagioclasa sódica $\left(\mathrm{An}_{18}\right)$, clorita y calcita. La plagioclasa progradante $\left(\mathrm{An}_{26-38}\right)$, es muy escasa y no tiene un desarrollo volumétrico considerable como el granate y piroxeno. Se presenta en agregados de pequeños cristales anhedrales menores a $1 \mathrm{~mm}$ y como frentes de reemplazo intersticial en el granito, observables únicamente bajo el microscopio en lámina delgada. Se encuentra fuertemente sericitizada y en menor grado reemplazada por clinozoisita en 
TABLA 3. MICROANÁLISIS DE BIOTITAS EN LOS DIQUES GÁBRICOS Y DIFERENCIADOS DIORÍTICOS (MUESTRA No. 558-09-04 Y N558-09-05, RESPECTIVAMENTE).

\begin{tabular}{|c|c|c|c|c|c|c|c|c|c|c|}
\hline \multirow{2}{*}{$\begin{array}{c}\begin{array}{c}\text { Muestra } \\
\text { No. }\end{array} \\
\% \text { peso }\end{array}$} & \multicolumn{4}{|c|}{ 558-09-04 } & \multicolumn{6}{|c|}{ 558-09-05 } \\
\hline & Bt1 & Bt2 & Bt3 & Bt4 & Bt5 & Bt6 & Bt7 & Bt8 & Bt9 & Bt10 \\
\hline $\mathrm{SiO}_{2}$ & 37,42 & 37,03 & 37,77 & 37,16 & 37,17 & 37,52 & 37,23 & 37,27 & 37,18 & 37,46 \\
\hline $\mathrm{TiO}_{2}$ & 1,96 & 1,83 & 1,61 & 2,09 & 1,84 & 2,45 & 2,09 & 1,90 & 2,51 & 1,96 \\
\hline $\mathrm{Al}_{2} \mathrm{O}_{3}$ & 16,45 & 16,94 & 16,67 & 16,56 & 17,25 & 16,80 & 16,14 & 15,89 & 14,81 & 16,01 \\
\hline $\mathrm{Fe}_{2} \mathrm{O}_{3}$ & - & - & - & - & - & - & - & - & - & - \\
\hline $\mathrm{FeO}$ & 16,80 & 16,93 & 16,66 & 17,77 & 16,77 & 17,34 & 16,70 & 16,73 & 18,61 & 18,81 \\
\hline $\mathrm{MgO}$ & 11,82 & 11,32 & 12,01 & 11,95 & 11,53 & 11,51 & 12,67 & 12,86 & 11,16 & 10,36 \\
\hline $\mathrm{MnO}$ & 0,07 & 0,06 & 0,16 & 0,12 & 0,10 & 0,13 & 0,10 & 0,21 & 0,05 & 0,16 \\
\hline $\mathrm{CaO}$ & 0,02 & 0,01 & 0,03 & 0,03 & 0,03 & 0,03 & 0,03 & 0,04 & 0,01 & nd \\
\hline $\mathrm{BaO}$ & 0,10 & 0,16 & 0,16 & 0,14 & 0,23 & 0,15 & 0,12 & nd & 0,09 & nd \\
\hline $\mathrm{Na}_{2} \mathrm{O}$ & 0,12 & 0,11 & 0,11 & 0,15 & 0,11 & 0,08 & 0,10 & 0,10 & 0,13 & 0,12 \\
\hline $\mathrm{K}_{2} \mathrm{O}$ & 9,52 & 9,48 & 9,32 & 8,93 & 9,41 & 9,58 & 9,16 & 9,48 & 9,15 & 9,48 \\
\hline $\mathrm{ZnO}$ & 0,12 & 0,04 & 0,03 & 0,10 & 0,00 & 0,11 & 0,12 & 0,11 & 0,05 & 0,12 \\
\hline F- & 0,10 & 0,18 & nd & 0,16 & 0,05 & 0,06 & 0,07 & 0,06 & 0,05 & 0,07 \\
\hline Cl- & 0,06 & 0,04 & 0,06 & 0,05 & 0,11 & 0,04 & 0,30 & 0,47 & 0,14 & 0,09 \\
\hline Total & 94,57 & 94,13 & 94,59 & 95,22 & 94,59 & 95,80 & 94,83 & 95,11 & 93,93 & 94,65 \\
\hline $\mathrm{O}=\mathrm{F}$ & 0,04 & 0,08 & nd & 0,07 & 0,02 & 0,02 & 0,03 & 0,02 & 0,02 & 0,03 \\
\hline $\mathrm{O}=\mathrm{Cl}$ & 0,01 & 0,01 & 0,01 & 0,01 & 0,02 & 0,01 & 0,07 & 0,11 & 0,03 & 0,02 \\
\hline $\mathrm{H}_{2} \mathrm{O}_{\text {calc. }}$ & 3,89 & 3,83 & 3,95 & 3,87 & 3,89 & 3,96 & 3,80 & 3,72 & 3,80 & 3,86 \\
\hline Total & 98,40 & 97,87 & 98,53 & 99,01 & 98,42 & 99,73 & 98,49 & 98,62 & 97,67 & 98,45 \\
\hline \multicolumn{11}{|c|}{ Cationes en base a 11 (O, F, Cl) } \\
\hline $\mathrm{Si}$ & 2,920 & 2,910 & 2,940 & 2,891 & 2,903 & 2,902 & 2,898 & 2,890 & 2,953 & 2,951 \\
\hline $\mathrm{Ti}$ & 0,115 & 0,108 & 0,094 & 0,122 & 0,108 & 0,143 & 0,122 & 0,111 & 0,150 & 0,116 \\
\hline${ }^{\mathrm{IV}} \mathrm{Al}$ & 0,965 & 0,982 & 0,966 & 0,987 & 0,989 & 0,955 & 0,980 & 0,999 & 0,897 & 0,933 \\
\hline${ }^{\mathrm{VI}} \mathrm{Al}$ & 0,548 & 0,587 & 0,564 & 0,532 & 0,599 & 0,577 & 0,501 & 0,453 & 0,489 & 0,554 \\
\hline $\mathrm{Fe}^{+3}$ & - & - & - & - & - & - & - & - & - & - \\
\hline $\mathrm{Fe}^{+2}$ & 1,096 & 1,113 & 1,085 & 1,156 & 1,095 & 1,122 & 1,087 & 1,085 & 1,236 & 1,239 \\
\hline $\mathrm{Mg}$ & 1,375 & 1,326 & 1,394 & 1,386 & 1,342 & 1,327 & 1,470 & 1,487 & 1,321 & 1,217 \\
\hline $\mathrm{Mn}$ & 0,005 & 0,004 & 0,010 & 0,008 & 0,007 & 0,008 & 0,007 & 0,014 & 0,003 & 0,011 \\
\hline $\mathrm{Ca}$ & 0,002 & 0,001 & 0,003 & 0,002 & 0,002 & 0,003 & 0,002 & 0,003 & 0,001 & 0,000 \\
\hline $\mathrm{Ba}$ & 0,000 & 0,000 & 0,000 & 0,000 & 0,000 & 0,000 & 0,000 & 0,000 & 0,000 & 0,000 \\
\hline $\mathrm{Na}$ & 0,018 & 0,017 & 0,016 & 0,023 & 0,017 & 0,012 & 0,015 & 0,015 & 0,019 & 0,019 \\
\hline K & 0,948 & 0,950 & 0,926 & 0,886 & 0,938 & 0,945 & 0,910 & 0,938 & 0,927 & 0,953 \\
\hline Zn & 0,007 & 0,002 & 0,002 & 0,006 & 0,000 & 0,006 & 0,007 & 0,006 & 0,003 & 0,007 \\
\hline $\mathrm{Fe} / \mathrm{Fe}+\mathrm{Mg}$ & 0,444 & 0,456 & 0,438 & 0,455 & 0,449 & 0,458 & 0,425 & 0,422 & 0,483 & 0,504 \\
\hline
\end{tabular}

nd: no detectado. $\mathrm{H}_{2} \mathrm{O}$ calculada. 


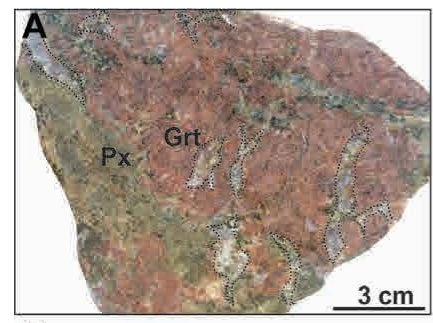

E

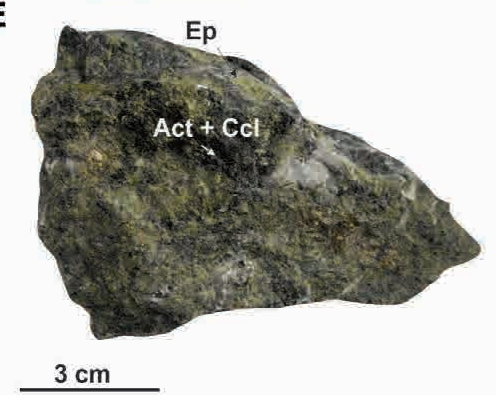

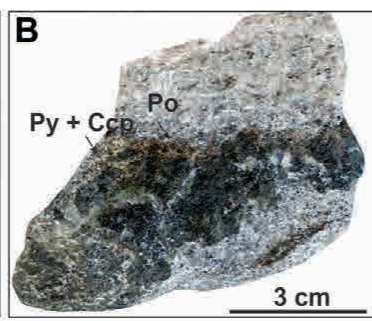

$\mathbf{F}$

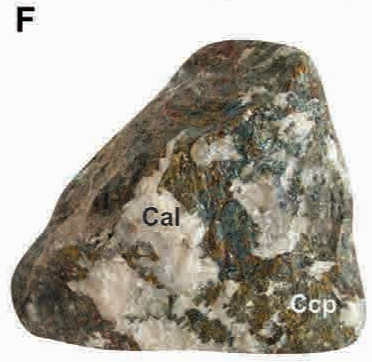

$3 \mathrm{~cm}$
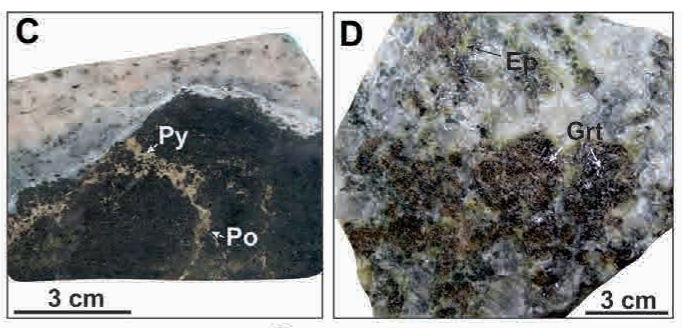

G

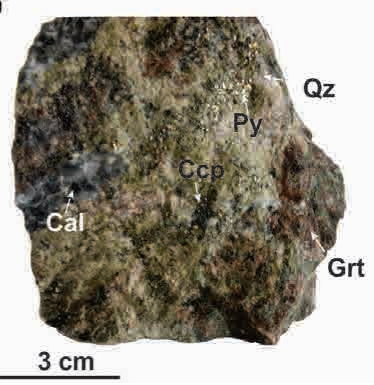

FIG. 4. Muestras de skarn de los frentes de explotación 548 y 558 de la Cantera Centro. A. Skarn de granate (Grt)-piroxeno (Px) de grano grueso y vetillas de cuarzo-calcita-pirita-calcopirita (señalado en líneas de puntos). B. Skarn de piroxeno con vetillas concordantes de pirita (Py), calcopirita (Ccp) y pirrotina (Po) en el contacto con el mármol cálcico. Las flechas señalan los sulfuros asociados al piroxeno. C. Superficie pulida de (B) mostrando venillas pseudo-concordantes de pirita (Py)-pirrotina (Po)-calcopirita (escasa) en el skarn de piroxeno en contacto con el mármol. D. Granate (Grt) con reemplazo de epidoto (Ep) en skarn de granate formado a partir del reemplazo de un mármol cálcico. E. Asociación retrogradante de epidoto (Ep)-anfíbol (Act)-clorita (Ccl) de grano grueso en skarn de piroxeno (véase el texto para mayor detalle). F. Vetilla de calcita (Cal) con calcopirita (Ccp) en skarn de granate- piroxeno. G. Asociación de relleno de cuarzo (Qz)-calcita (Cal)-pirita (Py)-calcopirita (Ccp) en skarn de granate- piroxeno.

granos anhedrales a subhedrales. También presenta bordes de reemplazo de plagioclasa más sódica $\left(A n_{18}\right)$. El granate se presenta en granos subhedrales a euhedrales, de $0,5 \mathrm{~mm}$ hasta $3 \mathrm{~cm}$ de diámetro. No se ha observado zonación composicional. Los análisis químicos revelan composiciones cálcicas con fuerte tendencia hacia los extremos subcálcicos ( $\mathrm{Grs}_{27-48} \mathrm{Adr}_{22-34} \mathrm{Alm}_{15-27} \mathrm{Sps}_{9-21}$, Tabla 4). La relación $\mathrm{Fe}^{+2} /\left(\mathrm{Fe}^{+2}+\mathrm{Fe}^{+3}\right)$ varía entre 0,41 y 0,64. Como alteración se observan agregados de calcita y epidoto que lo reemplazan desde la periferia, formando rebordes policristalinos (Fig. 5A), éste último observable también en muestras de mano. El epidoto perigranular presenta un contenido de Mn de 0,21\% a 0,37\% (Tabla 5).

El piroxeno es relativamente más escaso que el granate. Se halla en cristales subhedrales a euhedrales en tamaños que no exceden el centímetro de diámetro. Los análisis químicos exhiben proporciones molares predominantemente hedenbergíticas $\left(\mathrm{Hd}_{40-61} \mathrm{Di}_{35-}\right.$ ${ }_{54} \mathrm{Jo}_{4,7-6,4}$, Tabla 6). Se ha observado una zonación composicional en los cristales relacionada a un enriquecimiento en hierro hacia los bordes, con un núcleo relativamente más magnesiano; la relación $\mathrm{Fe} / \mathrm{Mg}$ varía de 0,55 a 1,25 de núcleo a borde y la relación $\mathrm{Fe}^{+2} /\left(\mathrm{Fe}^{+2}+\mathrm{Fe}^{+3}\right)$ varía de 0,72 a 0,91 . Muestra un fuerte reemplazo por epidoto y moderado reemplazo por actinolita. La cloritización es leve y afecta a piroxeno, epidoto y actinolita. El epidoto presenta rebordes de alteración de plagioclasa sódica $\left(\mathrm{An}_{18}\right)$ observables bajo el microscopio en lámina delgada. Los análisis químicos de la clorita muestran composiciones dentro del campo de la chamosita $(\mathrm{Fe} /[\mathrm{Fe}+\mathrm{Mg}]=0,58-0,69)$. Como minerales accesorios se reconocen escasa titanita y fluorapatita.

\subsubsection{Skarn de piroxeno}

Se origina a partir del reemplazo total de cuerpos lenticulares anfibolíticos (Fig. 1C) por piroxeno. Mediciones de campo realizadas durante 2014 en el frente de explotación 548, identificaron estos cuerpos de reemplazo de hasta un poco más de $3 \mathrm{~m}$ 


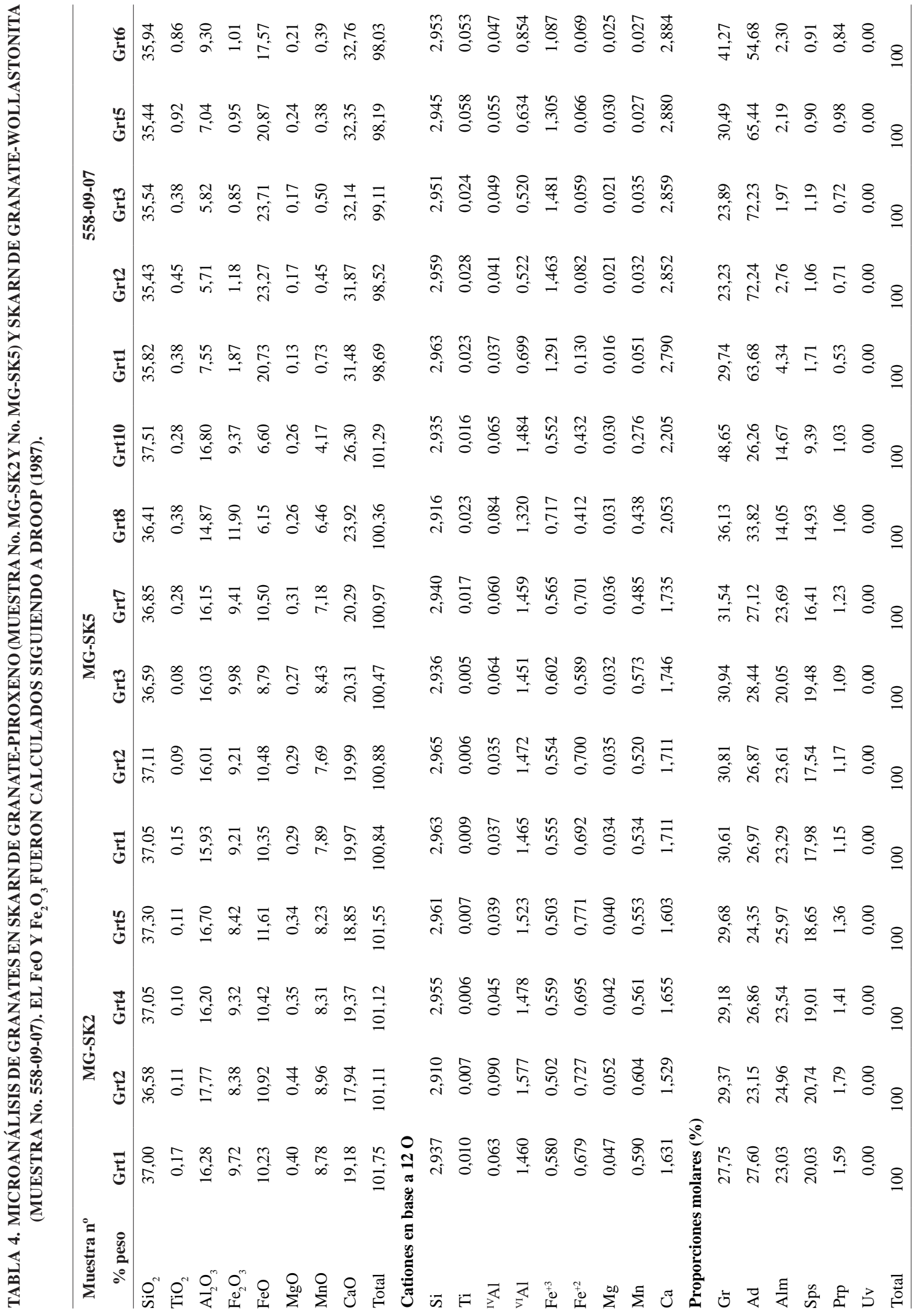



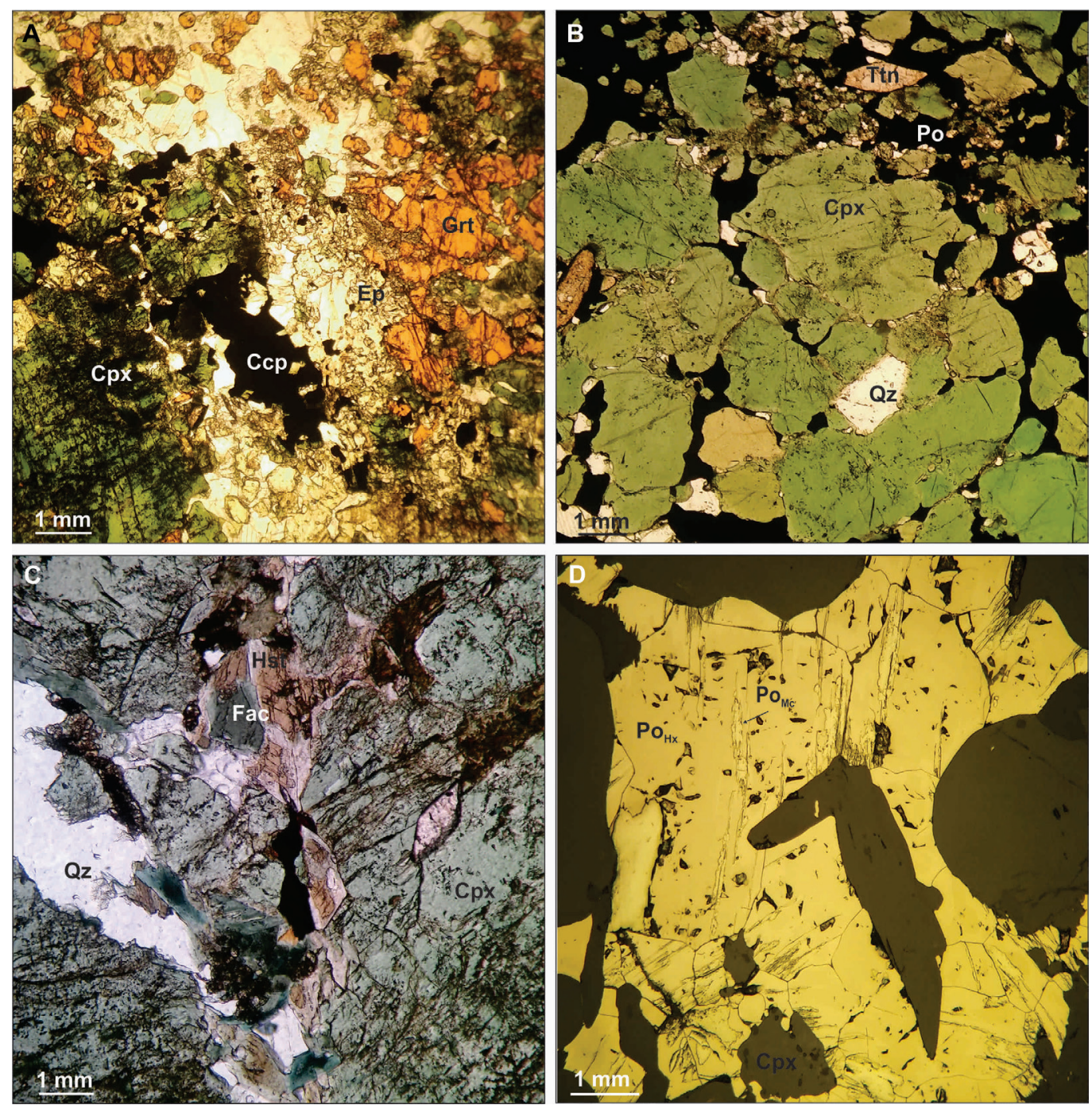

FIG. 5. A. Fotomicrografía de la asociación mineralógica del skarn de granate-piroxeno (luz refractada, nicoles paralelos). B. Fotomicrografía del skarn de piroxeno con matriz cementante de pirrotina (luz refractada, nicoles paralelos). C. Fotomicrografía mostrando la anfibolización de piroxenos y relleno de cuarzo y sulfuros en el skarn de piroxeno (luz refractada, nicoles paralelos). D. Fotomicrografía de pirrotina cementando a clinopiroxenos del skarn de piroxeno. Se pueden observar las exsoluciones de pirrotina hexagonal en pirrotina monoclínica pobre en hierro (luz relejada, nicoles paralelos). Cpx: clinopiroxeno; Grt: granate; Ep: epidoto; Ccp: calcopirita; Po: pirrotina; Qz: cuarzo; Ttn: titanita; Hst: hastingsita; Fac: ferroactinolita; $\mathbf{P o}_{\mathrm{Mc}}$ : pirrotina monoclínica; $\mathbf{P o}_{\mathrm{Hx}}$ : pirrotina hexagonal.

de espesor. La roca es prácticamente monomineral, compuesta esencialmente por clinopiroxenos. Es de color verde oscuro, presenta granulometría gruesa y textura esencialmente granoblástica. Los granos de piroxeno son euhedrales a subhedrales, de tamaños que no superan el centímetro de diámetro (Fig. 5B). Los análisis químicos indican composiciones dominantemente hedenbergíticas
$\left(\mathrm{Hd}_{46-61} \mathrm{Di}_{33-50} \mathrm{Jo}_{3-5}\right.$ Tabla 6), con una relación Fe/Mg entre 0,70 y 1,44 y una relación $\mathrm{Fe}^{+2} /\left(\mathrm{Fe}^{+2}+\mathrm{Fe}^{+3}\right)$ entre 0,74 y 0,89 que varían desde el núcleo hacia el borde del cristal. Como minerales accesorios se reconocen escasa titanita y fluorapatita. La alteración retrógrada corresponde a leve epidotización, reemplazo por actinolita y hastingsita y subordinada cloritización del clinopiroxeno (Fig. 5C, Tabla 2). 
TABLA 5. MICROANÁLISIS DE EPIDOTO EN SKARN DE GRANATE-PIROXENO (MUESTRA No. MG-SK2), SKARN DE PIROXENO (MUESTRA No. MG-M1) Y SKARN DE GRANATE-WOLLASTONITA(MUESTRA No. 558-09-07).

\begin{tabular}{|c|c|c|c|c|c|c|c|}
\hline \multirow{2}{*}{$\begin{array}{c}\text { Muestra No. } \\
\text { \% peso }\end{array}$} & \multirow{2}{*}{$\begin{array}{c}\text { MG-SK2 } \\
\text { Ep1 }\end{array}$} & \multicolumn{3}{|c|}{ MG-M1 } & \multicolumn{3}{|c|}{ 558-09-07 } \\
\hline & & Ep2 & Ep3 & Ep4 & Ep1 & Ep2 & Ep3 \\
\hline $\mathrm{SiO}_{2}$ & 37,09 & 36,71 & 36,97 & 37,29 & 37,06 & 37,36 & 37,50 \\
\hline $\mathrm{TiO}_{2}$ & 0,08 & 0,02 & 0,10 & 0,12 & 0,12 & 0,09 & 0,09 \\
\hline $\mathrm{Al}_{2} \mathrm{O}_{3}$ & 22,83 & 21,22 & 21,95 & 22,94 & 23,78 & 23,06 & 25,11 \\
\hline $\mathrm{Fe}_{2} \mathrm{O}_{3}$ & 13,88 & 15,78 & 14,33 & 14,22 & 12,55 & 12,70 & 11,02 \\
\hline $\mathrm{FeO}$ & - & - & - & - & - & - & - \\
\hline $\mathrm{MgO}$ & 0,03 & 0,00 & 0,02 & 0,02 & 0,01 & 0,02 & 0,02 \\
\hline $\mathrm{MnO}$ & 0,37 & 0,22 & 0,21 & 0,25 & 0,03 & 0,03 & 0,05 \\
\hline $\mathrm{CaO}$ & 22,79 & 23,31 & 23,14 & 23,33 & 22,94 & 22,49 & 23,28 \\
\hline Total & 97,07 & 97,26 & 96,72 & 98,17 & 95,23 & 94,48 & 95,97 \\
\hline $\mathrm{H}_{2} \mathrm{O}$ & 1,86 & 1,85 & 1,85 & 1,88 & 1,86 & 1,84 & 1,88 \\
\hline Total & 98,93 & 99,11 & 98,57 & 100,05 & 98,70 & 97,93 & 99,50 \\
\hline \multicolumn{8}{|c|}{ a.p.f.u. (7 cationes) } \\
\hline $\mathrm{Si}$ & 2,989 & 2,973 & 2,997 & 2,973 & 2,988 & 3,040 & 2,986 \\
\hline $\mathrm{Ti}$ & 0,005 & 0,001 & 0,003 & 0,007 & 0,007 & 0,006 & 0,005 \\
\hline${ }^{\mathrm{IV}} \mathrm{Al}$ & 0,006 & 0,025 & 0,000 & 0,020 & 0,005 & 0,000 & 0,000 \\
\hline${ }^{\mathrm{VI}} \mathrm{Al}$ & 2,162 & 2,000 & 2,096 & 2,135 & 2,254 & 2,211 & 2,356 \\
\hline $\mathrm{Fe}^{+3}$ & 0,842 & 0,962 & 0,874 & 0,853 & 0,761 & 0,778 & 0,661 \\
\hline $\mathrm{Fe}^{+2}$ & 0,000 & 0,000 & 0,000 & 0,000 & 0,000 & 0,000 & 0,000 \\
\hline Mg & 0,004 & 0,000 & 0,002 & 0,002 & 0,001 & 0,003 & 0,003 \\
\hline Mn & 0,025 & 0,015 & 0,015 & 0,017 & 0,002 & 0,002 & 0,004 \\
\hline $\mathrm{Ca}$ & 1,968 & 2,023 & 2,010 & 1,993 & 1,981 & 1,961 & 1,986 \\
\hline
\end{tabular}

nd: no detectado. $\mathrm{H}_{2} \mathrm{O}$ calculada. El FeO y $\mathrm{Fe}_{2} \mathrm{O}_{3}$ fueron calculados siguiendo a Droop (1987).

La epidotización se presenta como agregados de cristales euhedrales a subhedrales de epidoto de algunos milímetros de tamaño en los contactos intergranulares de piroxeno. Superpuesta a esta alteración, se observa una anfibolización representada por dos fases bien diferenciadas: 1) La fase primaria se presenta como pequeños cristales de hastingsita menores a $1 \mathrm{~mm}$ que reemplazan al piroxeno preferentemente en sus bordes o a través de fracturas intragranulares; 2) La segunda especie es ferroactinolita que reemplaza a ambas fases anteriores, y que constituye agregados fibrosos asociados a venillas de calcita-clinocloro-cuarzopirita-calcopirita.

\subsubsection{Skarn de granate ( \pm wollastonita)}

Se produce por el reemplazo de hasta un metro de espesor del protolito carbonático. La asociación mineralógica del skarn está compuesta principalmente por granate intercrecido con escasa wollastonita. Los cristales de granate, de algunos milímetros de diámetro, son euhedrales, y presentan, al igual que aquellos formados en el granito, reemplazo con rebordes policristalinos de epidoto. La wollastonita es muy escasa y se encuentra en agregados fibrosos de hasta $0,5 \mathrm{~mm}$ de largo reemplazados por carbonato y minoritariamente clinozoisita; algunos agregados se hallan incluidos en escapolita. Los análisis químicos del granate señalan 
TABLA 6. MICROANÁLISIS DE CLINOPIROXENOS EN SKARN DE GRANATE-PIROXENO (MUESTRA No. MGSK5) Y SKARN DE PIROXENO (MUESTRA No. MG-M1).

\begin{tabular}{|c|c|c|c|c|c|c|c|c|c|c|c|c|c|c|c|c|c|}
\hline \multirow{2}{*}{$\begin{array}{c}\text { Muestra } \\
\text { No. } \\
\% \text { peso }\end{array}$} & \multirow[b]{2}{*}{ Cpx1 } & \multicolumn{8}{|c|}{ MG-SK5 } & \multicolumn{8}{|c|}{ MG-M1 } \\
\hline & & Cpx2 & Сpx4 & Cpx7 & Сpx8 & Срх9 & Cpx11 & Cpx12 & 2Сpx13 & Cpx1 & Cpx4 & Cpx5 & Сpx6 & Cpx7 & Cpx9 & Cpx12 & Cpx13 \\
\hline $\mathrm{SiO}_{2}$ & 50,67 & 50,91 & 49,75 & 50,52 & 50,19 & 51,35 & 49,59 & 49,56 & 52,02 & 51,60 & 50,13 & 50,49 & 50,69 & 50,03 & 48,37 & 48,85 & 49,05 \\
\hline $\mathrm{TiO}_{2}$ & 0,01 & 0,05 & nd & nd & 0,05 & nd & 0,01 & 0,05 & nd & 0,01 & 0,08 & 0,08 & 0,02 & 0,04 & 0,10 & 0,11 & 0,08 \\
\hline $\mathrm{Al}_{2} \mathrm{O}_{3}$ & 0,90 & 1,01 & 1,69 & 1,05 & 1,19 & 0,67 & 1,58 & 1,60 & 0,32 & 1,02 & 1,46 & 1,65 & 1,46 & 1,52 & 2,43 & 2,11 & 2,04 \\
\hline $\mathrm{Fe}_{2} \mathrm{O}_{3}$ & 4,12 & 2,03 & 2,71 & 2,71 & 2,70 & 1,39 & 3,69 & 3,37 & 1,39 & 1,72 & 3,37 & 3,10 & 3,05 & 2,72 & 4,34 & 4,39 & 4,01 \\
\hline $\mathrm{FeO}$ & 9,57 & 11,75 & 14,03 & 11,26 & 12,22 & 11,98 & 14,48 & 13,73 & 10,18 & 12,29 & 12,07 & 12,63 & 12,35 & 13,63 & 14,28 & 13,93 & 14,30 \\
\hline $\mathrm{MgO}$ & 9,33 & 8,81 & 7,08 & 8,70 & 7,97 & 9,23 & 6,56 & 6,90 & 10,28 & 9,18 & 8,37 & 8,18 & 8,48 & 7,58 & 6,11 & 6,46 & 6,26 \\
\hline $\mathrm{MnO}$ & 1,82 & 1,74 & 1,90 & 1,85 & 2,09 & 1,67 & 1,62 & 1,87 & 2,15 & 1,11 & 1,24 & 1,27 & 1,29 & 1,31 & 1,67 & 1,47 & 1,44 \\
\hline $\mathrm{CaO}$ & 22,51 & 22,80 & 21,61 & 23,08 & 22,75 & 23,06 & 21,87 & 22,04 & 23,69 & 22,48 & 22,10 & 22,10 & 22,00 & 21,89 & 21,24 & 21,43 & 21,56 \\
\hline $\mathrm{Na}_{2} \mathrm{O}$ & 0,56 & 0,51 & 70 & 0,46 & 0,50 & 0 & 0,74 & 0,68 & 0,25 & 0,66 & 0,73 & 0,79 & 0,77 & 0,74 & 0,85 & 0,91 & 0,90 \\
\hline $\mathrm{Cr}_{2} \mathrm{O}_{3}$ & 0,01 & 0,01 & 0,01 & nd & nd & 0,02 & nd & 0,03 & no & 0,01 & nd & 0,01 & nd & nd & 0,01 & 0,04 & 0,01 \\
\hline $\mathrm{NiO}$ & $\mathrm{n}$ & 01 & 04 & nd & 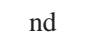 & nd & nd & 0 & nd & 0,0 & The & 0,0 & no & nd & nd & 0,03 & d \\
\hline Total & 99,49 & 99,63 & 99,53 & 99,63 & 99,65 & 99,77 & 100,14 & 99,87 & 100,29 & 100,11 & 99,56 & 100,33 & 100,12 & 99,46 & 99,41 & 99,73 & 99,65 \\
\hline \multicolumn{18}{|c|}{ Cationes en base a 60} \\
\hline $\mathrm{Si}$ & 1,958 & 1,967 & 1,946 & 1,955 & 1,952 & 1,977 & 1,938 & 1,937 & 1,982 & 1,977 & 1,944 & - 1,944 & 1,952 & 1,951 & 1,907 & 1,915 & 1,925 \\
\hline $\mathrm{Ti}$ & 0,000 & 0,001 & 0,000 & 0,000 & 0,001 & 0,000 & 0,000 & 0,001 & 0,000 & 0,000 & 0,002 & 0,002 & 0,001 & 0,001 & 0,003 & 0,003 & 0,002 \\
\hline${ }^{\mathrm{IV}} \mathrm{Al}$ & 0,041 & 0,032 & 0,054 & 0,045 & 0,047 & 0,023 & 0,062 & 0,062 & 0,018 & 0,023 & 0,054 & 0,054 & 0,047 & 0,048 & 0,090 & 0,082 & 0,072 \\
\hline${ }^{\mathrm{VI}} \mathrm{Al}$ & 0,000 & 0,000 & 0,000 & 0,000 & 0,000 & 0,000 & 0,000 & 0,000 & 0,000 & 0,000 & 0,000 & 0,000 & 0,000 & 0,000 & 0,000 & 0,000 & 0,000 \\
\hline $\mathrm{Fe}^{+3}$ & 20 & 0,060 & 0,080 & 0,080 & 0,080 & 0,040 & 0,110 & 0,100 & 0,040 & 0,050 & 0,100 & 0,090 & 0,0 & 0,080 & 0,130 & 0,130 & 0,120 \\
\hline $\mathrm{Fe}^{+2}$ & 0,310 & 0,386 & 51 & 0,370 & 03 & 84 & 0 & 0 & 5 & 0 & 0 & 0 , & 0 & 46 & 0 & 0,459 & 0,476 \\
\hline $\mathrm{Mg}$ & 0,538 & 0,507 & 0,413 & 0,502 & 0,462 & 0,530 & 0,382 & 0,402 & 0,584 & 0,524 & 0,484 & . 0,469 & 0,487 & 0,441 & 0,359 & 0,378 & 0,366 \\
\hline Mn & 0,060 & 0,057 & 0,063 & 0,061 & 0,069 & 554 & 0,054 & 0 , & 99 & 0,036 & 0,041 & 0 , & 0,042 & 0,043 & 0,056 & 0,049 & 0,048 \\
\hline Ca & 0,932 & 0,944 & 0,906 & 0,957 & 0,948 & 0,951 & 0,916 & 0,923 & 0,967 & 0,923 & 0,918 & 0,912 & 0,908 & 0,914 & 0,897 & 0,900 & 0,907 \\
\hline $\mathrm{Na}$ & 0,042 & 0,038 & 0,053 & 0,034 & 0,037 & 0,030 & 0,056 & 0,051 & 0,019 & 0,049 & 0,055 & 0,059 & 0,057 & 0,056 & 0,065 & 0,069 & 0,069 \\
\hline $\mathrm{Cr}$ & 0,000 & 0,000 & 0,000 & 0,000 & 0,000 & 0,001 & 0,000 & 0,001 & 0,000 & 0,000 & 0,000 & 0,000 & 0,000 & 0,000 & 0,000 & 0,001 & 0,000 \\
\hline $\mathrm{Ni}$ & 0,000 & 0,000 & 0,001 & 0,000 & 0,000 & 0,000 & 0,000 & 0,001 & 0,000 & 0,001 & 0,000 & 0,001 & 0,000 & 0,000 & 0,000 & 0,001 & 0,000 \\
\hline \multicolumn{18}{|c|}{ Proporciones molares (\%) } \\
\hline Di & 49 & 40 & 38 & 47 & 43 & 50 & 35 & 37 & 54 & 50 & 46 & 45 & 46 & 42 & 33 & 35 & 35 \\
\hline Hd & 45 & 47 & 56 & 48 & 51 & 45 & 60 & 57 & 40 & 46 & 51 & 51 & 50 & 54 & 61 & 60 & 61 \\
\hline Jo & 5 & 5 & 6 & 0 & 0 & 5 & 5 & 6 & 6 & 3 & 4 & 4 & 4 & 4 & 5 & 5 & 5 \\
\hline tal & 00 & 0 & 100 & 100 & 00 & 0 & 100 & 100 & 100 & 100 & 100 & 100 & 100 & 100 & 100 & 100 & 100 \\
\hline
\end{tabular}

nd: no detectado. El FeO y $\mathrm{Fe}_{2} \mathrm{O}_{3}$ fueron calculados siguiendo a Droop (1987).

composiciones predominantemente andradíticas $\left(\mathrm{Adr}_{50-}\right.$ ${ }_{70} \mathrm{Grs}_{20-40} \mathrm{Alm}_{5-7} ;$ Tabla 4). El epidoto de esta zona posee, a diferencia del epidoto de reemplazo de los granates del granito, menos de 0,05\% de Mn (Tabla 5). También se observan venillas de escapolita intercrecidas con cuarzo, de hasta $10 \mathrm{~cm}$ de longitud y $2 \mathrm{~cm}$ de ancho, que se disponen alineadas pseudo-concordantemente en el skarn de granate ( \pm wollastonita) y en el mármol. 


\subsubsection{Vetas y vetillas de calcita-clinocloro-cuarzo portadoras de sulfuros}

Los sulfuros presentes en los skarns se restringen a vetas y vetillas pseudoconcordantes y como agregados cristalinos macizos que constituyen lentes y cuerpos de forma irregular. La mayor parte de los sulfuros presentes en el área de estudio se hallan en vetas y vetillas de hasta $2 \mathrm{~cm}$ de espesor y un par decímetros de largo, compuestas en orden de abundancia por cuarzo, calcita y clorita en las cuales se distribuye pirita, calcopirita, pirrotina y esfalerita. Los cuerpos macizos de sulfuros están restringidos al skarn de piroxeno y constituyen lentes que alcanzan espesores de hasta 0,3 $\mathrm{m}$ y un par de metros de longitud. El cuarzo de las vetas/vetillas es subhedral, de grano fino a medio (desde $0,1 \mathrm{~mm}$ hasta $3 \mathrm{~mm}$ ) y se encuentra intercrecido con calcita subhedral de grano fino (desde $50 \mu \mathrm{m}$ hasta $0,5 \mathrm{~mm}$ ), aunque hay cristales romboédricos que desarrollan caras cristalinas de hasta un par de centímetros de largo. Ocasionalmente la calcita se presenta como inclusiones dentro de cristales de sulfuros. La clorita, en agregados con hábito en acordeón o laminar-radial, se distribuye principalmente a lo largo de los contactos intergranulares del mosaico poligranular de carbonato. Los análisis químicos de la clorita, en conjunto con los análisis de difracción de rayos $\mathrm{X}$, permiten clasificarla como clinocloro $(\mathrm{Fe} /[\mathrm{Fe}+\mathrm{Mg}]=0,37-0,38)$, a diferencia de la clorita de la asociación retrógrada que es chamosita (Tabla 6). En contacto con las vetas existe clinozoisita, que se presenta como cristales prismáticos euhedrales de hasta 0,5 mm de largo, con caras cristalinas que rematan hacia el cuarzo, calcita y sulfuros de las vetillas; sin embargo, este mineral se desarrolla preferentemente como cristales subhedrales de reemplazo junto a epidoto y anfíboles y es interpretado como representativo de la asociación retrogradante.

La pirita se distribuye en vetillas con cristales euhedrales a subhedrales que miden entre $0,5 \mathrm{y}$ $5 \mathrm{~mm}$. Algunos cristales presentan inclusiones de cuarzo y/o calcita. La calcopirita también forma parte de las vetillas y puede contener inclusiones de pirita euhedral, y aparecen, además, como agregados cristalinos que constituyen vetillas muy finas que se distribuyen a lo largo de los planos de clivaje/ fractura de los cristales de piroxeno. La esfalerita se halla íntimamente asociada a la calcopirita; presenta pequeñas inclusiones de este mineral, conformando la conocida textura en disease; también ocurre como pequeñas inclusiones euhedrales de hasta $0,2 \mathrm{~mm}$ en cristales de calcopirita de hasta $3 \mathrm{~mm}$ de diámetro. Como alteración de la calcopirita, se reconoce covellina.

El sulfuro predominante en el skarn de piroxeno es la pirrotina maciza que rodea como un agregado intergranular cementante a los cristales de piroxeno. Son conspicuas las texturas de exsolución lamelar en pirrotina entre las fases de alta y baja temperatura, correspondientes a la transformación de pirrotina hexagonal (58,9-59,9\% de Fe) a pirrotina monoclínica pobre en hierro (46-47\% de Fe; Fig. 5D, Tabla 7, e.g., Einaudi, 1971; Craig y Scott, 1982; Lianxing y Vokes, 1996). Las muestras de pirrotina que presentan estas exsoluciones son magnéticas; esto concuerda con la propiedad ferromagnética de la pirrotina monoclínica (Becker et al., 1997). Los siguientes valores de celda unidad obtenidos por difracción de rayos $\mathrm{X}$ evidencian la presencia de ambas fases (valores en $\AA$ ): $a=11,902, b=6,859, c=22,787$ y a $=3,440$, $b=3,440, c=5,760$; las reflexiones de las dos fases guardan correspondencia con las de los patrones 01-089-1954 y 00-024-0220, respectivamente, de la base de datos del JCPDS-ICDD (Joint Committee on Powder Diffraction Standards-International Centre for Diffraction Data), versión 2003 (Tabla 8). En menor proporción se observan cristales subhedrales a euhedrales de calcopirita y pirita de hasta un par de mm incluidos en pirrotina. Los sulfuros se encuentran débilmente oxidados.

En muestras extraídas de los frentes de la Cantera Centro, se han observado escasos agregados cristalinos de fluorita con tintes azulinos de hasta $1 \mathrm{~cm}$, distribuidos como parches irregulares en la asociación retrogradante y a modo de inclusión en una vena de cuarzo; si bien no se ha identificado este mineral bajo lámina delgada, su vínculo con la asociación mineral tardía lo ubicaría en las etapas finales de la etapa retrogradante. Asociada al mármol metasomatizado, se han observado vetillas de escapolita intercrecida con cuarzo, a cuyo estadio se asocia la cristalización de fluorita.

\subsubsection{Contenido metalífero en muestras de las unidades litológicas.}

Los resultados de los análisis químicos de muestras de los diques máficos y anfibolita (no afectadas por metasomatismo) y del skarn de piroxeno mineralizado con pirrotina, pirita y calcopirita se presentan en la tabla 9. 
TABLA 7. MICROANÁLISIS DE CLORITA DE REEMPLAZO A PARTIR DE EPIDOTO, ANFÍBOLES, PIROXENOS Y GRANATES (MUESTRA No. MG-SK2) Y DE RELLENO ASOCIADA A QZ-CAL-CLZ-PO-PY-CCP-SP (MUESTRA No. MG-SK4).

\begin{tabular}{|c|c|c|c|c|c|c|}
\hline \multirow{2}{*}{$\begin{array}{c}\text { Muestra No. } \\
\% \text { peso }\end{array}$} & \multicolumn{6}{|c|}{ MG-SK4 } \\
\hline & Chl1 & Chl2 & Chl4 & Chl6 & Chl7 & Chl10 \\
\hline $\mathrm{SiO}_{2}$ & 26,99 & 27,21 & 27,18 & 26,84 & 27,03 & 26,86 \\
\hline $\mathrm{TiO}_{2}$ & 0,03 & 0,02 & nd & 0,02 & nd & 0,04 \\
\hline $\mathrm{Al}_{2} \mathrm{O}_{3}$ & 19,89 & 19,84 & 19,65 & 19,79 & 19,83 & 19,34 \\
\hline $\mathrm{Fe}_{2} \mathrm{O}_{3}$ & 0,64 & 0,52 & 0,26 & 1,16 & nd & 1,91 \\
\hline $\mathrm{FeO}$ & 19,78 & 20,16 & 19,84 & 19,91 & 19,71 & 19,33 \\
\hline $\mathrm{MgO}$ & 18,61 & 18,48 & 18,73 & 18,56 & 18,52 & 17,87 \\
\hline $\mathrm{MnO}$ & 2,09 & 2,30 & 2,16 & 2,02 & 1,94 & 2,39 \\
\hline $\mathrm{CaO}$ & 0,05 & 0,12 & 0,07 & 0,03 & nd & 0,02 \\
\hline $\mathrm{BaO}$ & nd & nd & nd & nd & nd & nd \\
\hline $\mathrm{Na}_{2} \mathrm{O}$ & 0,05 & 0,03 & 0,01 & 0,01 & 0,02 & 0,04 \\
\hline $\mathrm{K}_{2} \mathrm{O}$ & 0,00 & 0,02 & nd & 0,03 & nd & 0,01 \\
\hline $\mathrm{ZnO}$ & 0,18 & 0,13 & 0,12 & 0,16 & 0,07 & 0,09 \\
\hline F- & nd & nd & nd & 0,01 & 0,07 & nd \\
\hline Cl- & nd & 0,01 & nd & 0,01 & nd & 0,01 \\
\hline Total & 88,33 & 88,85 & 88,02 & 88,55 & 87,19 & 87,90 \\
\hline $\mathrm{O}=\mathrm{F}$ & 0,00 & 0,00 & 0,00 & 0,01 & 0,03 & 0,00 \\
\hline $\mathrm{O}=\mathrm{Cl}$ & 0,00 & 0,00 & 0,00 & 0,00 & 0,00 & 0,00 \\
\hline $\mathrm{H}_{2} \mathrm{O}_{\text {calc. }}$ & 11,61 & 11,66 & 11,62 & 11,55 & 11,52 & 11,39 \\
\hline Total & 99,93 & 100,51 & 99,64 & 100,09 & 98,69 & 99,29 \\
\hline \multicolumn{7}{|c|}{ Cationes en base a 140} \\
\hline $\mathrm{Si}$ & 2,774 & 2,785 & 2,800 & 2,759 & 2,778 & 2,811 \\
\hline $\mathrm{Ti}$ & 0,003 & 0,001 & 0,000 & 0,001 & 0,000 & 0,003 \\
\hline${ }^{\mathrm{IV}} \mathrm{Al}$ & 1,223 & 1,213 & 1,200 & 1,240 & 1,222 & 1,186 \\
\hline${ }^{\mathrm{VI}} \mathrm{Al}$ & 1,187 & 1,180 & 1,186 & 1,157 & 1,180 & 1,199 \\
\hline $\mathrm{Fe}^{+3}$ & 0,050 & 0,040 & 0,020 & 0,090 & 0,000 & 0,150 \\
\hline $\mathrm{Fe}^{+2}$ & 1,708 & 1,728 & 1,715 & 1,717 & 1,694 & 1,689 \\
\hline $\mathrm{Mg}$ & 2,852 & 2,820 & 2,877 & 2,844 & 2,838 & 2,788 \\
\hline Mn & 0,182 & 0,199 & 0,188 & 0,176 & 0,169 & 0,212 \\
\hline $\mathrm{Ca}$ & 0,000 & 0,000 & 0,000 & 0,000 & 0,000 & 0,000 \\
\hline $\mathrm{Ba}$ & 0,006 & 0,014 & 0,008 & 0,004 & 0,000 & 0,002 \\
\hline $\mathrm{Na}$ & 0,009 & 0,006 & 0,002 & 0,003 & 0,004 & 0,009 \\
\hline $\mathrm{K}$ & 0,000 & 0,003 & 0,000 & 0,004 & 0,000 & 0,002 \\
\hline $\mathrm{Zn}$ & 0,014 & 0,010 & 0,009 & 0,012 & 0,005 & 0,007 \\
\hline $\mathrm{Fe} /(\mathrm{Fe}+\mathrm{Mg})$ & 0,375 & 0,380 & 0,373 & 0,376 & 0,374 & 0,377 \\
\hline
\end{tabular}

nd: no detectado. $\mathrm{H}_{2} \mathrm{O}$ calculado. El FeO y $\mathrm{Fe}_{2} \mathrm{O}_{3}$ fue calculado siguiendo a Droop (1987).

Los contenidos de $\mathrm{Cr}$ alcanzan hasta 150 ppm en el gabro y $50 \mathrm{ppm}$ en la diorita; los valores de $\mathrm{Cu}$ para estas rocas son de 290 y 230 ppm, respectivamente; para el $\mathrm{Zn}$ se observa un contenido máximo de 140 ppm en el gabro y menor para su diferenciado diorítico (60 ppm). Los afloramientos de rocas máficas en las Sierras de Córdoba que podrían asemejarse a estos diques, desde un punto de vista mineralógico y químico, son los del metagabro Cañada del Puerto y sus diferenciados cumuláticos peridotíticos y anortosíticos estudiados por Lucero Michaut y Daziano (1984) y Gaido y Miró (1998); sin embargo, los contenidos de $\mathrm{Cu}$ y $\mathrm{Zn}$ hallados en las metabasitas de Cañada del Puerto (Cu: 14-131 ppm 
TABLA 8. ESPACIADOS RETICULARES EN Å E INTENSIDAD EN \% DE LOS DIFRACTOGRAMAS DE PIRROTINA HEXAGONAL Y MONOCLÍNICA OBTENIDOS COMPARADOS CON LOS PATRONES DE REFERENCIA.

\begin{tabular}{|c|c|c|c|c|c|c|c|}
\hline \multicolumn{2}{|c|}{ Po (H) } & \multicolumn{2}{|c|}{$00-024-0220$} & \multicolumn{2}{|c|}{ Po (M) } & \multicolumn{2}{|c|}{ 01-089-1954 } \\
\hline $\mathbf{d}[\AA]]$ & Rel. Int. [\%] & d [Å] & Rel. Int. [\%] & d [Å] & Rel. Int. [\%] & d [ [Å] & Rel. Int. [\%] \\
\hline 2,06675 & 100,00 & 2,05500 & 100,00 & 2,63164 & 100,00 & 2,62930 & 75,3 \\
\hline 2,64066 & 81,02 & 2,63500 & 55,00 & 2,05586 & 86,13 & 2,05240 & 100,00 \\
\hline 2,97509 & 63,43 & 2,97400 & 54,00 & 2,96963 & 90,40 & 2,97140 & 77,00 \\
\hline 1,71776 & 43,80 & 1,71680 & 33,00 & 1,71838 & 33,35 & 1,71710 & 60,00 \\
\hline 1,32254 & 9,73 & 1,31760 & 10,00 & - & - & - & - \\
\hline 5,70650 & 6,48 & 5,68700 & 8,00 & - & - & - & - \\
\hline 1,60706 & 6,33 & 1,59850 & 6,00 & - & - & - & - \\
\hline
\end{tabular}

TABLA 9. ANÁLISIS QUÍMICOS DE ELEMENTOS MAYORITARIOS Y TRAZAS PERTENECIENTES A LOS DIQUES GÁBRICOS (MUESTRA No. 558-09-04), DIORÍTICOS (MUESTRA No. 558-09-05), ANFIBOLITA (MUESTRA No. 558-09-B) Y MUESTRA DE SKARN MINERALIZADA CON SULFUROS (MLGN-SULF).

\begin{tabular}{|c|c|c|c|c|}
\hline$\%$ en peso & 558-09-04 & 558-09-05 & 558-09-b & Mlgn-sulf \\
\hline $\mathrm{SiO}_{2}$ & 49,46 & 58 & 48,11 & 41,23 \\
\hline $\mathrm{Al}_{2} \mathrm{O}_{3}$ & 16,55 & 19,45 & 15,11 & 9,32 \\
\hline $\mathrm{Fe}_{2} \mathrm{O}_{3}(\mathrm{~T})$ & 16,3 & 5,65 & 10,22 & 21,06 \\
\hline $\mathrm{MnO}$ & 0,114 & 0,044 & 0,167 & 0,404 \\
\hline $\mathrm{MgO}$ & 3,95 & 1,25 & 9,28 & 2,62 \\
\hline $\mathrm{CaO}$ & 6,13 & 7,43 & 10,61 & 12,51 \\
\hline $\mathrm{Na}_{2} \mathrm{O}$ & 2,58 & 3,66 & 2,83 & 0,59 \\
\hline $\mathrm{K}_{2} \mathrm{O}$ & 2,1 & 1,06 & 1,35 & 0,11 \\
\hline $\mathrm{TiO}_{2}$ & 1,718 & 0,724 & 1,016 & 0,627 \\
\hline $\mathrm{P}_{2} \mathrm{O}_{5}$ & 0,08 & 0,21 & 0,09 & 0,13 \\
\hline PPC & 0,92 & 1,22 & 1,76 & 5,58 \\
\hline Total & 99,9 & 98,69 & 100,6 & 94,19 \\
\hline V & 238 & 77 & 201 & 60 \\
\hline $\mathrm{Cr}$ & 150 & 40 & 470 & 20 \\
\hline $\mathrm{Ni}$ & 90 & 30 & 200 & 110 \\
\hline $\mathrm{Cu}$ & 290 & 230 & 920 & 23.000 \\
\hline $\mathrm{Zn}$ & 140 & 60 & 90 & 940 \\
\hline $\mathrm{Ag}$ & 5,1 & 3,4 & 0,5 & 5,5 \\
\hline $\mathrm{Au}^{*}$ & na & na & 49 & 82 \\
\hline
\end{tabular}

*: ppb; <: “menor a”; PPC: Pérdida por calcinación; n.a: no analizado. Los elementos trazas se encuentran en ppm. 
y Zn: 61-104 ppm), son significativamente menores que los obtenidos en este trabajo.

La anfibolita de Cantera Centro muestra contenidos altos de Cu, Cr, Ni y V (920, 470, 200 y 201 ppm, respectivamente) y $90 \mathrm{ppm}$ de $\mathrm{Zn}$, lo que contrasta con los contenidos informados por Daziano (2004) para las anfibolitas de la Sierra Chica de Córdoba, con valores máximos de Cu de 240 ppm y 187 ppm de Zn.

Los resultados del análisis de elementos minoritarios y trazas en la muestra de skarn mineralizado con sulfuros, indican concentraciones de $\mathrm{Cu}$ de 2,3\% y 900 ppm de Zn. Los valores analíticos Ag y Au son de 5,5 ppm y $82 \mathrm{ppb}$, respectivamente (Tabla 9). Comparativamente, las leyes de estos elementos para la mina Tío del distrito Calamuchita, son los que más se aproximan a los obtenidos en el área de estudio, con una media de Cu de 2,5\%, 1.360 ppm de Zn y 3,2 ppm de Ag. Para el resto de los depósitos de cobre de la provincia de Córdoba, las leyes medias de cobre varían de 1,4\%, para las canteras del distrito Cañada de Álvarez hasta 7,23\% en la mina Tauro, del distrito Calamuchita. Los contenidos de Zn son variables, aunque las mayores concentraciones no superan los 1.400 ppm. Los valores de Ag también son variables, habiéndose registrado desde $0,8 \mathrm{~g} / \mathrm{t}$ en la mina Cuchi Corral del distrito Punilla, hasta $3 \mathrm{~g} / \mathrm{t}$ en la mina Aída (Mutti y Di Marco, 1999).

\section{Geotermometría}

Las relaciones texturales de la clorita que integra la asociación mineral de las vetas y vetillas portadoras de sulfuros (Qz-Cal-Clc- sulfuros) indican que esta fase fue formada tardíamente a partir de los fluidos hidrotermales que formaron el skarn. Esta condición permite utilizar el potencial geotermométrico de este mineral, a partir de la relación Fe/Mg versus $\mathrm{Al}^{\mathrm{IV}}$ acorde a los criterios de Cathelineau y Nieva (1985), Cathelineau (1988), Jowett (1991), De Caritat et al. (1993) y Battaglia (1999) y constatado previamente que $\Sigma$ Ca-Na-K es, en todos los casos $<0,2$, hecho que sugiere que las cloritas analizadas no están contaminadas con otras potenciales fases interestratificadas (e.g., Jiang et al., 1994; Frimmel, 1997). Los cálculos geotermométricos a partir de Cathelineau (1988) y Jowett (1991), dan un rango térmico de cristalización del clinocloro comprendido entre $340{ }^{\circ} \mathrm{C}$ y $320{ }^{\circ} \mathrm{C}$, mientras que el cálculo geotermométrico siguiendo los principios de Battaglia
(1999), a partir del espaciado $\mathrm{d}_{001}$ obtenido por difractometría de rayos $\mathrm{X}$ de una muestra de polvo, arroja una temperatura de cristalización de $279^{\circ} \mathrm{C}$.

\section{Microtermometría de inclusiones fluidas}

Se realizaron mediciones en 35 inclusiones fluidas alojadas en cristales de calcita, que forman parte de la secuencia paragenética de las vetas de calcita+clinocloro+cuarzo+pirita+pirrotina+calcop irita+ esfalerita, representativa de la fase tardía de relleno de skarn. Las muestras a partir de las cuales se extrajeron los cristales de calcita corresponden a vetas emplazadas en el skarn de granate-piroxeno. Las inclusiones fluidas primarias son mayoritariamente bifásicas líquido-vapor $(\mathrm{L}+\mathrm{V})$, con cantidades subordinadas de inclusiones bifásicas vapor-líquido $(\mathrm{V}+\mathrm{L})$, trifásicas líquido-vapor-sólido (cristal hijo) $(\mathrm{L}+\mathrm{V}+\mathrm{S})$, polifásicas $\left(\mathrm{L}+\mathrm{V}+\mathrm{S}_{1}+\mathrm{S}_{2}+\mathrm{S}_{3}\right)$, e inclusiones monofásicas ( $\mathrm{V}$ y L). Existen poblaciones de inclusiones fluidas secundarias alineadas según planos que atraviesan los contactos poligranulares y algunas que se cortan entre sí; éstas han sido interpretadas como secundarias y no consideradas en este estudio. Las inclusiones fluidas primarias se distribuyen aisladas o en grupos de manera heterogénea en los granos de calcita. Las inclusiones bifásicas $\mathrm{L}+\mathrm{V}$ consideradas primarias se hallan dispuestas al azar con una morfología romboédrica a subredondeada y tamaños variables entre 3 y $15 \mu \mathrm{m}$ aproximadamente; el grado de llenado de estas inclusiones oscila entre 70 y $85 \%$.

Las inclusiones bifásicas $(\mathrm{V}+\mathrm{L})$ y monofásicas ricas en vapor (V) están presentes tanto en inclusiones primarias como secundarias. Las inclusiones bifásicas primarias $(\mathrm{V}+\mathrm{L})$ miden entre 5 y $30 \mu \mathrm{m}$ con grados de llenado entre $\sim 0 \%$ y $50 \%$, es decir con relaciones $\mathrm{L} / \mathrm{V}$ entre $\sim 0$ y 0,5 . Estas inclusiones ricas en fase vapor se encuentran formando parte de las poblaciones dominadas porcentualmente por inclusiones ricas en líquido con grados de llenado variable entre $70 \mathrm{y}$ 85\%, saturadas o no con respecto a halita (Fig. 6A). Esta evidencia, junto al hecho que unas pocas hayan homogeneizado a fase vapor dentro del mismo rango térmico que las restantes de la misma población, favorece su interpretación como resultantes de un proceso de ebullición.

Las inclusiones trifásicas presentan un grado de llenado entre 75 y 90\% y los cristales hijos corresponden a cubos de halita (Fig. 6B, C), algunos 
con trazas de K identificadas por EDS (Fig. 6D). Estas inclusiones presentan una morfología romboédrica a redondeada con tamaños que van de $5 \mu \mathrm{m}$ a 35 $\mu \mathrm{m}$ aproximadamente, aunque se han observado inclusiones de morfología alargada de hasta $100 \mu \mathrm{m}$. Las inclusiones polifásicas presentan, además de cristales de halita, cristales hijos de morfología irregular de hasta $20 \mu \mathrm{m}$ identificados por EDS, en inclusiones abiertas, como sulfatos de Sr y Ba (Fig. 6D) y otros más pequeños (hasta $1 \mu \mathrm{m}$ ) correspondientes a cristales opacos de galena y sulfuros de $\mathrm{Fe}$ (Fig. 6D, E); en varias inclusiones fluidas estos diminutos cristales hijos de sulfuros han actuado como núcLeos de cristalización de los cubos de halita (Fig. 6B). Los cristales hijos con presencia de S, O, Sr y/o Ba (Fig. 6D) han sido interpretados como sulfatos (serie baritina - celestina). Una inclusión sólida idiomorfa de hábito tabular que registra por EDS la presencia de $\mathrm{S}, \mathrm{O}, \mathrm{Pb}(+\mathrm{Fe})$, fue interpretada como probable anglesita (Fig. 6F). A partir de imágenes de electrones retrodispersados (BSE) en cavidades que corresponden a inclusiones fluidas abiertas, se observó la presencia de precipitados salinos clorurados (EDS= $\mathrm{Na}>>\mathrm{K}$ ) concéntricos, depositados por evaporación de los fluidos derramados en la periferia de las cavidades (i.e., evaporative mounds, Fig. 6G).

En adición a la petrografía de inclusiones fluidas en cristales de calcita, se observaron inclusiones menores a $5 \mu \mathrm{m}$ portadoras de cristales de halita y otras fases sólidas no identificadas en cuarzo de relleno asociado paragenéticamente a calcita, clorita, pirita, calcopirita y pirrotina.

Se efectuaron mediciones de enfriamiento calentamiento, para determinar la salinidad del sistema y establecer el rango térmico de temperaturas mínimas de entrampamiento (temperaturas de homogeneización), junto con mediciones de temperatura de fusión de cristales de halita en inclusiones trifásicas y polifásicas para determinar la salinidad en condiciones saturadas (Tabla 10). Los resultados obtenidos muestran un rango de temperaturas de homogeneización a líquido que oscila entre 217,0 y $359,2{ }^{\circ} \mathrm{C}$ con una
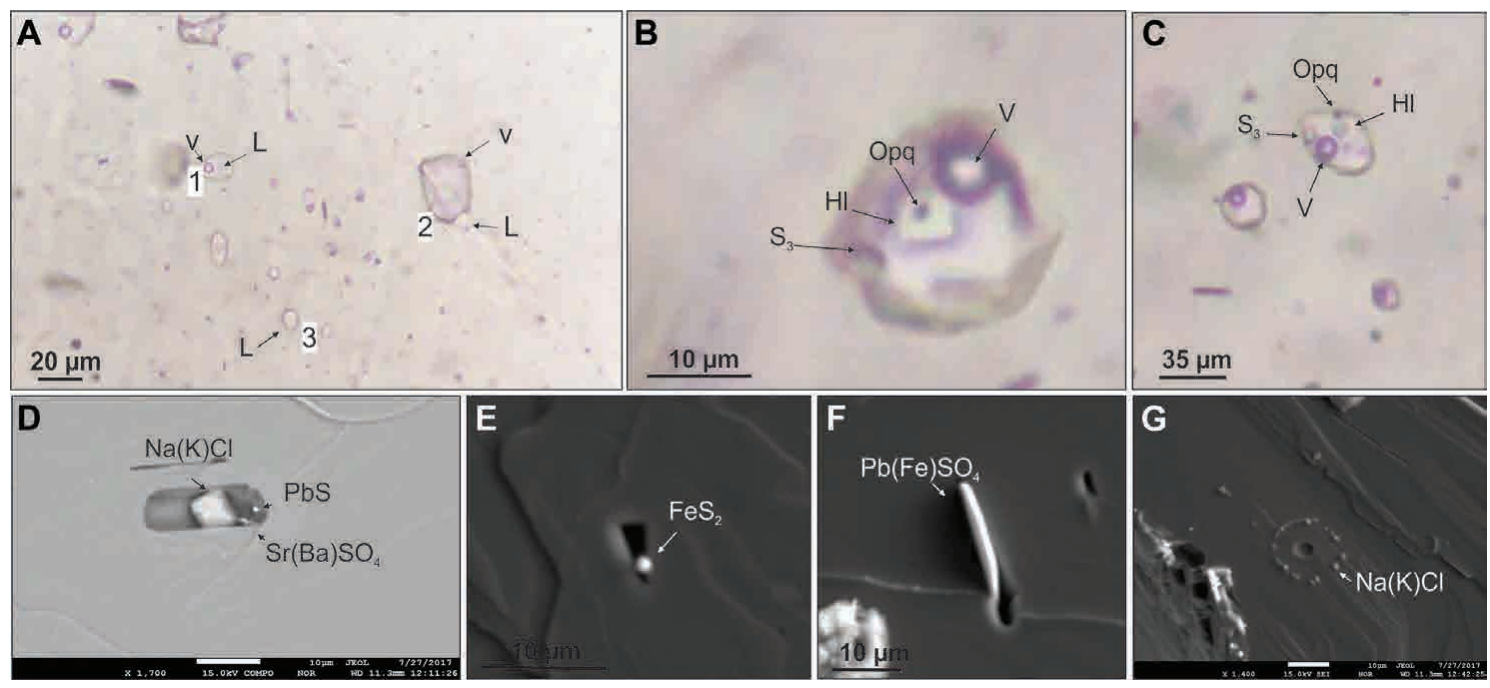

FIG. 6. Inclusiones fluidas en calcita de las vetillas portadoras de sulfuros en la asociación mineral de relleno tardía de skarn. A. Inclusiones bifásicas líquido-vapor L+V (señalada con el No. 1) alargadas a subredondeadas coexistentes con inclusiones bifásicas V+L (señalada con el No. 2) e inclusiones monofásicas L (señalada con No. 3). B. Inclusión polifásica subredondeada. El cristal de halita ( $\mathrm{Hl}$ ) presenta un núcleo de cristalización de un probable sulfuro (Opq) y está asociado a una fase desconocida $\mathrm{S}_{3}$ (posiblemente un sulfato). C. Inclusión polifásica similar a b junto a inclusiones bifásicas L+V redondeadas. El mineral opaco (Opq) se halla libre en el líquido o implantado en la pared de la cavidad. D. Imagen de electrones retrodispersados (BSE) de una cavidad abierta de una inclusión polifásica con cristales hijos identificados por EDS. E. Sulfuro de hierro como cristal hijo en una cavidad de una inclusión fluida abierta. F. Inclusión sólida alargada de sulfato de plomo y hierro. Debido a la relación de tamaños y morfologías entre cristal y cavidad, se interpreta que la formación de la inclusión fluida fue consecuencia del entrampamiento accidental de la inclusión sólida. G. Precipitados salinos clorurados alineados concéntricamente en la periferia de una cavidad de una inclusión abierta producidos durante la pérdida del líquido entrampado (evaporative mounds). L: líquido; V: vapor. Las figuras E, F y G son imágenes de electrones secundarios (SEI). 
media que ronda los $300{ }^{\circ} \mathrm{C}$ aproximadamente (Fig. 7A). Además se ha obtenido la temperatura de homogeneización de una inclusión fluida a fase vapor a $357,3{ }^{\circ} \mathrm{C}$ y otra con tendencia a homogeneizar a fase vapor que decrepitó tempranamente a $218,4^{\circ} \mathrm{C}$. Las temperaturas de fusión del último cristal de hielo oscilan entre $-1,0$ y $-11,9^{\circ} \mathrm{C}$, equivalentes a salinidades calculadas en el rango 1,7 y $15,9 \%$ en peso de $\mathrm{NaCl}$ eq., respectivamente; las temperaturas de fusión de 4 cristales de halita obtenidos a una temperatura comprendida entre 221,2 y $244,2^{\circ} \mathrm{C}$ indican salinidades de 33 y 34,3\% en peso de $\mathrm{NaCl}$ eq. Se manifiestan así tres familias bien diferenciadas de salinidades dentro de la misma población: 1) Una de baja salinidad y densidad con promedio de $2,75 \%$ en peso de $\mathrm{NaCl}$ eq. y $\left.1,0 \mathrm{~g} / \mathrm{cm}^{3} ; 2\right)$ Otra de moderada salinidad y densidad cuyo promedio alcanza los $14,5 \%$ en peso de $\mathrm{NaCl}$ eq. y $1,1 \mathrm{~g} / \mathrm{cm}^{3}$; y 3) Una de alta salinidad representada por inclusiones trifásicas y polifásicas con una salinidad promedio de 33,55\% en peso de $\mathrm{NaCl}$ eq. (Fig. 7B). Ha sido difícil obtener medidas de homogeneización a fase líquida en las inclusiones saturadas en halita, habiendo todas, excepto un par, decrepitado parcial o totalmente antes de la disolución completa del cristal de halita, en el intervalo térmico de $\sim 237,6$ a $303,7^{\circ} \mathrm{C}$. Las medidas que escaparon a la decrepitación permitieron obtener 4 disoluciones de halita (221, 1 a 244, $2^{\circ} \mathrm{C}$ ) poco antes de la decrepitación parcial o total $\left(\sim 247{ }^{\circ} \mathrm{C}, 20\right.$ a $30{ }^{\circ} \mathrm{C}$ más que los valores de disolución); estos datos demuestran que las temperaturas de homogeneización a fase líquida son más altas que la temperaturas de la disolución de halita, aunque no se ha podido calcular cuánto más altas; sin embargo, las salinidades calculadas sugieren que las inclusiones se ubicarían sobre la curva o fuera del campo de saturación de halita (Fig. 7A); en este último caso la mayoría de las inclusiones saturadas en halita serían metaestables (Shepherd et al., 1985).

\section{Composición isotópica del azufre}

Los análisis de isótopos estables de azufre se realizaron en 6 muestras de sulfuros asociados a las vetas de Qz-Cal-Clc de la fase de relleno en el skarn de granate-piroxeno y skarn de piroxeno. Las muestras analizadas corresponden a dos muestras de pirita, una de calcopirita y una de pirrotina. Los resultados obtenidos se detallan en la tabla 11. Los valores de $\delta^{34} \mathrm{~S}_{\mathrm{V}-\mathrm{CDT}} \%$ en pirrotina dan una media de $-3,0 \%$ y en pirita -2,8\%; la calcopirita, en cambio, muestra valores algo más pesados con una media de $+1,4 \%$. Es sabido que estos valores isotópicos son controlados por la composición isotópica total de los fluidos que les dieron origen $\left(=\delta^{34} S_{\sum \text { fluido }}\right.$ ), mayoritariamente resultante de la composición isotópica $\left(\delta^{34} \mathrm{~S}\right)$ y la fracción molar $\left(\mathrm{X}_{\mathrm{i}}\right)$ en el sistema de los distintos compuestos oxidados y reducidos del S (e.g., S'-2, $\mathrm{HS}^{-}, \mathrm{H}_{2} \mathrm{~S}, \mathrm{SO}_{4}^{2-}, \mathrm{HSO}_{4}^{-}, \mathrm{KSO}_{4}^{-}$ y $\mathrm{NaSO}_{4}^{-}$) y por otros parámetros como temperatura, Eh y pH que dependen del ambiente en el lugar de la mineralización (Sakai, 1968; Rye y Ohmoto, 1974; Ohmoto y Rye, 1979; Kerrich, 1987). Los valores de $\delta^{34} S_{\Sigma \text { fluido }}$ fueron calculados a partir del factor de fraccionamiento de Ohmoto y Rye (1979), considerando un sistema dominado por especies reducidas y $\mathrm{pH}$ neutros a alcalinos $\left(\mathrm{H}_{2} \mathrm{~S} /\left[\mathrm{H}_{2} \mathrm{~S}+\mathrm{SO}_{4}^{2-}\right]=0,99 ; \mathrm{X}_{\mathrm{H} 2 \mathrm{~S}}=0,99\right.$ $\left.\mathrm{y} \mathrm{X}_{\mathrm{SO}_{4}}{ }^{2-}=0,01\right)$. Esta relación molar es la que mejor se ajusta al cálculo de $\delta^{34} \mathrm{~S}_{\Sigma \text { ffuido }}$ en el rango de $300^{\circ} \mathrm{C}$ hasta $150^{\circ} \mathrm{C}$, ya que presenta valores similares para pirrotina y pirita desde $-3,09$ a $-4,67 \%$ o de $+1,42 \%$ promedio para calcopirita.

\section{Discusión}

La presencia de vetas y vetillas portadoras de sulfuros presentes en la Cantera Malagueño se encuentra restringida a cuerpos de skarn de granatepiroxeno y de piroxeno, desarrollados en los bordes de un metagranito y anfibolitas, respectivamente. Esta asociación espacial entre skarn y vetillas/vetas portadoras de sulfuros, que excluye su presencia en el resto de las litologías del área de estudio, sugiere, además de la relación espacial, un vínculo genético entre ambos. La presencia de estas vetillas/vetas que cortan las asociaciones progradantes del skarn también son indicativas que las fases sulfuradas se habrían depositado en una etapa tardía del proceso metasomático que originó el skarn (Fig. 8).

\subsection{Condiciones de formación de las vetas y vetillas de sulfuros}

Los ensayos de microtermometría en inclusiones fluidas en calcita, en conjunto con los datos geotermométricos de clinocloro asociado a calcita en las vetillas con sulfuros, indican un rango de temperatura entre $\sim 360^{\circ} \mathrm{C}$ y $250^{\circ} \mathrm{C}$ para el evento tardío que aportó sulfuros de $\mathrm{Fe}-\mathrm{Cu}-\mathrm{Zn}$ al skarn presente en la Cantera Malagueño. Este rango de temperatura es, adicionalmente, compatible con la coexistencia de pirrotina hexagonal, rica en hierro, 
TABLA 10. DATOS MICROTERMOMÉTRICOS DE INCLUSIONES FLUIDAS.

\begin{tabular}{|c|c|c|c|c|c|c|c|c|c|c|}
\hline $\begin{array}{c}\text { Muestra } \\
\text { No. }\end{array}$ & $\mathbf{N}^{\circ}$ I.F. & Fases & Morfología & $\begin{array}{c}\text { Tamaño* } \\
(\mu \mathrm{m})\end{array}$ & $\begin{array}{c}\text { Grado de } \\
\text { Ilenado (\%) }\end{array}$ & $\begin{array}{r}\mathbf{T}^{\circ} \mathbf{h} \\
\left({ }^{\circ} \mathbf{C}\right)\end{array}$ & $\begin{array}{l}\mathbf{T}^{\circ} \mathbf{f} \\
\left({ }^{\circ} \mathbf{C}\right)\end{array}$ & $\begin{array}{l}\mathrm{T}^{\circ} \mathbf{m} \\
\left({ }^{\circ} \mathbf{C}\right)\end{array}$ & $\begin{array}{c}\text { \% en peso } \\
\text { NaCl eq. }\end{array}$ & $\begin{array}{l}\text { Densidad del fluido } \\
\left.\text { (g/ } \mathrm{cm}^{3}\right)\left(\text { a } 25^{\circ} \mathrm{C}\right)\end{array}$ \\
\hline \multirow[t]{10}{*}{1} & 1 & $\mathrm{~L}+\mathrm{V}$ & cristal (-) & 5 & 80 & 280,2 & - & $-1,20$ & 2,07 & 1,02 \\
\hline & 2 & $\mathrm{~L}+\mathrm{V}$ & irregular & 15 & 70 & 284,9 & - & $-1,10$ & 1,9 & 1,02 \\
\hline & 3 & $\mathrm{~L}+\mathrm{V}$ & cristal (-) & 5 & 60 & 348,0 & - & $-1,80$ & 3,06 & 1,03 \\
\hline & 4 & $\mathrm{~L}+\mathrm{V}$ & irregular & 10 & 70 & 359,2 & - & $-1,70$ & 2,9 & 1,03 \\
\hline & 5 & $\mathrm{~L}+\mathrm{V}$ & irregular & 10 & 85 & 287,0 & - & $-10,40$ & 14,36 & 1,12 \\
\hline & 6 & $\mathrm{~L}+\mathrm{V}$ & irregular & 12 & 75 & 304,8 & - & $-1,70$ & 2,9 & 1,03 \\
\hline & 7 & $\mathrm{~L}+\mathrm{V}$ & cristal (-) & 10 & 75 & 356,3 & - & $-9,40$ & 13,29 & 1,11 \\
\hline & 8 & $\mathrm{~L}+\mathrm{V}$ & cristal (-) & 5 & 60 & 260,0 & - & $-10,60$ & 14,56 & 1,12 \\
\hline & 9 & $\mathrm{~L}+\mathrm{V}$ & irregular & 12 & 75 & 271,1 & - & $-11,90$ & 15,86 & 1,13 \\
\hline & 10 & $\mathrm{~L}+\mathrm{V}$ & irregular & 12 & 85 & 217,0 & - & $-2,20$ & 3,71 & 1,03 \\
\hline \multirow[t]{15}{*}{2} & 11 & $\mathrm{~L}+\mathrm{V}$ & cristal (-) & 5 & 75 & 311,6 & - & $-1,90$ & 3,23 & 1,03 \\
\hline & 12 & $\mathrm{~L}+\mathrm{V}$ & cristal (-) & 10 & 80 & 290,2 & - & $-1,60$ & 2,73 & 1,03 \\
\hline & 13 & $\mathrm{~L}+\mathrm{V}$ & irregular & 15 & 50 & 294,7 & - & $-2,30$ & 3,86 & 1,03 \\
\hline & 14 & $\mathrm{~L}+\mathrm{V}$ & irregular & 10 & 75 & 286,7 & - & - & - & - \\
\hline & 15 & $\mathrm{~L}+\mathrm{V}$ & cristal (-) & 10 & 70 & 287,6 & - & $-1,30$ & 2,24 & 1,02 \\
\hline & 16 & $\mathrm{~L}+\mathrm{V}$ & irregular & 10 & 80 & 292,3 & - & - & - & - \\
\hline & 17 & $\mathrm{~L}+\mathrm{V}$ & irregular & 12 & 80 & 335,2 & - & - & - & - \\
\hline & 18 & $\mathrm{~L}+\mathrm{V}$ & irregular & 5 & 80 & 286,2 & - & - & - & - \\
\hline & 19 & $\mathrm{~L}+\mathrm{V}$ & cristal (-) & 10 & 80 & 305,3 & - & - & - & - \\
\hline & 20 & $\mathrm{~L}+\mathrm{V}$ & irregular & 10 & 70 & 320,9 & - & $-1,70$ & 2,9 & 1,03 \\
\hline & 21 & $\mathrm{~L}+\mathrm{V}$ & irregular & 15 & 85 & 321,1 & - & $-2,00$ & 3,39 & 1,03 \\
\hline & 22 & $\mathrm{~L}+\mathrm{V}$ & irregular & 15 & 80 & - & - & $-1,50$ & 2,57 & 1,02 \\
\hline & 23 & $\mathrm{~L}+\mathrm{V}$ & irregular & 12 & 85 & - & - & $-2,00$ & 3,39 & 1,03 \\
\hline & 24 & $\mathrm{~L}+\mathrm{V}$ & irregular & 5 & 80 & 318,2 & - & $-1,00$ & 1,74 & 1,02 \\
\hline & 25 & $\mathrm{~L}+\mathrm{V}$ & irregular & 5 & 75 & 318,7 & - & $-1,50$ & 2,57 & 1,02 \\
\hline \multirow[t]{10}{*}{3} & 26 & $\mathrm{~V}+\mathrm{L}$ & irregular & 15 & 10 & 218,4 (D) & - & - & - & - \\
\hline & 27 & $\mathrm{~V}+\mathrm{L}$ & irregular & 15 & 15 & 357,3 & - & - & - & - \\
\hline & 29 & $\mathrm{~L}+\mathrm{V}+\mathrm{S}$ & irregular & 15 & 70 & 246,6 (D) & 232 & - & 33,6 & - \\
\hline & 30 & $\mathrm{~L}+\mathrm{V}+\mathrm{S}$ & irregular & 15 & 75 & 247 (D) & 244,2 & - & 34,3 & - \\
\hline & 31 & $\mathrm{~L}+\mathrm{V}+\mathrm{S}$ & irregular & 10 & 80 & - & 226,2 & - & 33,3 & - \\
\hline & 32 & $\mathrm{~L}+\mathrm{V}+\mathrm{S}$ & irregular & 5 & 80 & - & 221,1 & - & 33 & - \\
\hline & 33 & $\mathrm{~L}+\mathrm{V}$ & cristal (-) & 10 & 75 & 237,6 (D) & - & - & - & - \\
\hline & 34 & $\mathrm{~L}+\mathrm{V}$ & cristal (-) & 10 & 75 & 237,6 (D) & - & - & - & - \\
\hline & 35 & $\mathrm{~L}+\mathrm{V}+\mathrm{S}$ & cristal (-) & 5 & 80 & 276,5 (D) & - & - & - & - \\
\hline & 36 & $\mathrm{~L}+\mathrm{V}+\mathrm{S}$ & cristal (-) & 5 & 80 & 303,7 (D) & - & - & - & - \\
\hline
\end{tabular}

(*) Aproximadamente, Grado de llenado: \% L/V, L: Líquido, V: Vapor, S: Sólido, Tº $\mathbf{h}$ : Temperatura de homogeneización (Temperatura de entrampamiento mínima), $\mathbf{T}^{\circ} \mathbf{m}$ : Temperatura de fusión del último cristal de hielo, $\mathbf{T}^{\circ} \mathbf{f}$ : Temperatura de fusión de cristal de halita, D: Decrepitada. 

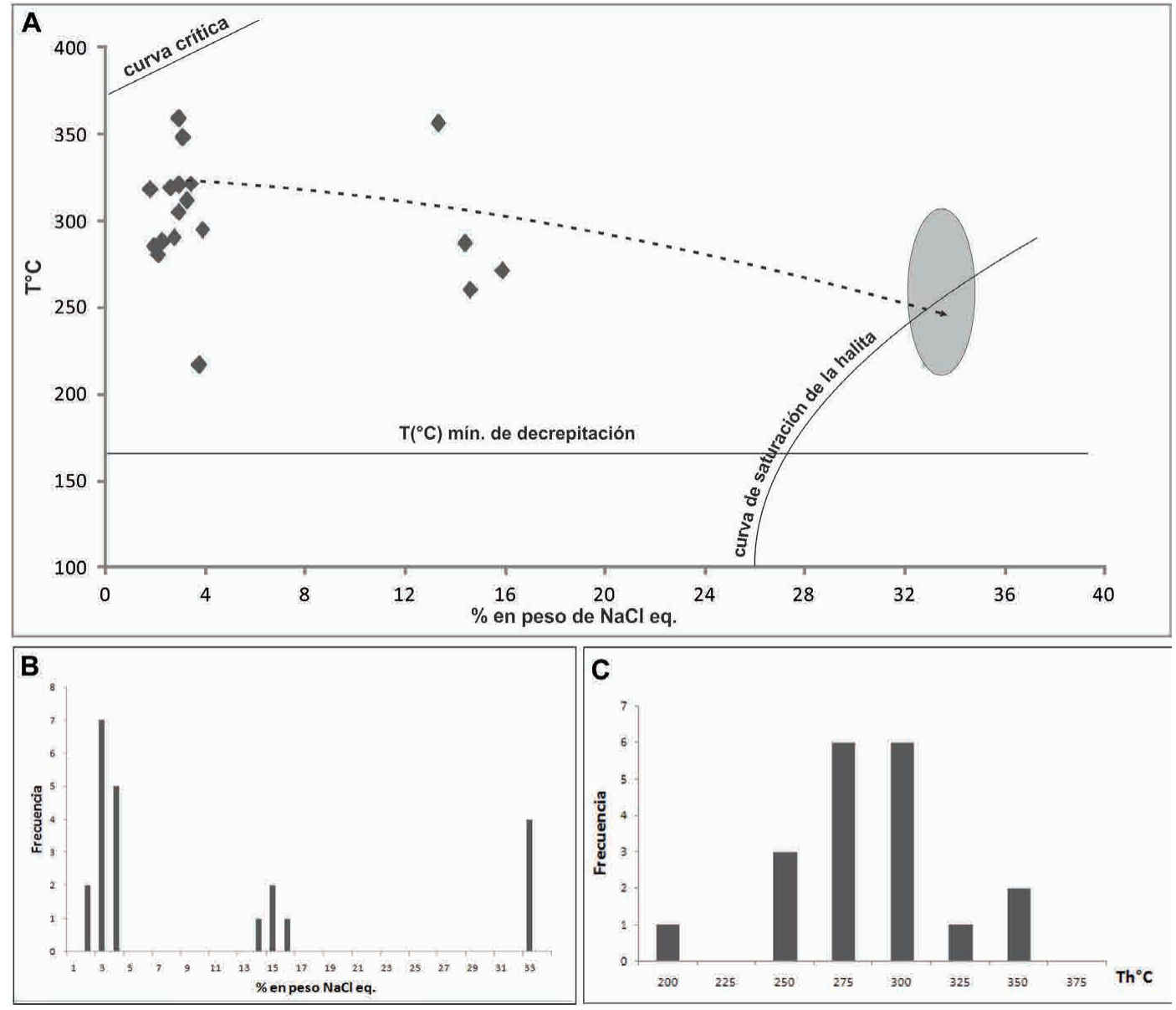

FIG. 7. A. Diagrama temperatura $\left(\mathrm{T}^{\circ} \mathrm{C}\right)$ - salinidad (\% en peso $\mathrm{NaCl}$ eq.) de las inclusiones fluidas medidas; el elipsoide gris encierra las temperaturas de decrepitación mínima y máxima obtenidas en las inclusiones trifásicas y polifásicas. B. Histograma de frecuencias de salinidades (\% en peso $\mathrm{NaCl}$ eq.) mostrando las tres familias de poblaciones de baja, media y alta salinidad. C. Histograma de frecuencias de temperatura de homogeneización $\left(\mathrm{T}^{\circ} \mathrm{C}\right)$.

con exsoluciones de pirrotina monoclínica, pobre en hierro, para lo cual se sugiere una temperatura de cristalización de $254{ }^{\circ} \mathrm{C}$ (Kissin y Scott, 1982). Este rango térmico concuerda con las relaciones texturales que señalan que la secuencia de precipitación de la paragénesis del evento mineralizador es: calcita $\rightarrow$ clinocloro $\rightarrow$ cuarzo $\rightarrow$ pirita $\rightarrow$ pirrotina $\rightarrow$ calcopirita 土esfalerita (Fig. 8).

La coexistencia de inclusiones fluidas de diferentes salinidades (baja, moderada y saturada en $\mathrm{NaCl}$ ) en una misma población, en conjunto con las evidencias petrográficas de las inclusiones fluidas (e.g., grado de llenado) y la homogeneización a fase vapor de algunas de ellas, sugiere un proceso de ebullición.
Éste produjo la separación de inclusiones fluidas ricas en vapor, con salinidades bajas, de otras más ricas en líquido subsaturadas a saturadas en $\mathrm{NaCl}$ (e.g., Roedder, 1984; Shepperd et al., 1985; Kwak, 1986; Wilkinson, 2001).

Este proceso de ebullición también podría haber sido el mecanismo que indujo a la saturación y precipitación de las fases sulfuradas de cobre y hierro $( \pm \mathrm{Zn})$ en íntima asociación con calcita (e.g., Drummond y Ohmoto 1985). Si bien no se ha observado galena en los skarns estudiados, la presencia de este sulfuro ha sido mencionada en vetas de cuarzo presentes en zonas aledañas (e.g., Cantera 10, Fig. 1). La coexistencia de sulfuros y sulfatos ( $\mathrm{Sr}$ y/o $\mathrm{Ba}$ ) 
TABLA 11. COMPOSICIÓN ISOTÓPICA DEL AZUFRE EN SULFUROS (PIRROTINAPIRITA-CALCOPIRITA) DE LA FASE DE RELLENO DE SKARN. $\mathbf{X}_{\mathrm{SO} 4} \mathbf{Y ~ X}_{\mathrm{H} 2 \mathrm{~S}}$ FRACCIONES MOLARES, $\Delta^{34} \mathrm{~S}_{\text {TOTAL }}=\Delta^{34} \mathrm{~S}_{\text {¿FLUIDO }}$

\begin{tabular}{|c|c|c|c|c|c|}
\hline & \multirow{2}{*}{$\delta^{34} S_{\mathrm{V}-\mathrm{CDT}}(\%)$} & \multicolumn{4}{|c|}{$\delta^{34} S_{\text {total }}$} \\
\hline & & $300^{\circ} \mathrm{C}$ & $250{ }^{\circ} \mathrm{C}$ & $200^{\circ} \mathrm{C}$ & $150{ }^{\circ} \mathrm{C}$ \\
\hline Py & $-2,98$ & \multirow[b]{2}{*}{$-3,79$} & \multirow[b]{2}{*}{$-4,00$} & \multirow[b]{2}{*}{$-4,28$} & \multirow[b]{2}{*}{$-4,67$} \\
\hline Py & $-2,61$ & & & & \\
\hline Po & $-3,05$ & \multirow{2}{*}{$-3,09$} & \multirow{2}{*}{$-3,12$} & \multirow{2}{*}{$-3,16$} & \multirow{2}{*}{$-3,21$} \\
\hline Po & $-2,98$ & & & & \\
\hline Сср & 1,07 & \multirow{2}{*}{1,42} & \multirow{2}{*}{1,42} & \multirow{2}{*}{1,42} & \multirow{2}{*}{1,42} \\
\hline Сср & 1,64 & & & & \\
\hline $\mathrm{X}_{\mathrm{SO} 4}$ & 0,01 & - & - & - & - \\
\hline $\mathrm{X}_{\mathrm{H} 2 \mathrm{~S}}$ & 0,99 & - & - & - & - \\
\hline
\end{tabular}

como cristales hijos y el probable sulfato de $\mathrm{Pb} \pm \mathrm{Fe}$ de entrampamiento accidental en las inclusiones fluidas, posiblemente reflejen la oxidación parcial del $\mathrm{H}_{2} \mathrm{~S}$ presente en la solución, producida por la ebullición durante la precipitación de calcita (e.g., Barnes, 1979); la ebullición provocaría reacciones de intercambio con los complejos portadores de metales y precipitación, en muy baja concentración, de sulfatos insolubles ( $\mathrm{Pb} \pm \mathrm{Fe}, \mathrm{Sr}, \mathrm{Ba})$. Asumiendo que los metales que forman las vetillas/vetas en Malagueño fueron transportados en solución como complejos clorurados, la reacción de intercambio podría ejemplificarse en la ecuación (1) (Barnes, 1979):

(1) $(\mathrm{Fe}, \mathrm{Pb}) \mathrm{Cl}_{\mathrm{n}}{ }^{2-\mathrm{n}}{ }_{\text {(ac) }}+\mathrm{H}_{2} \mathrm{~S}_{(\text {(ac) }}+2 \mathrm{O}_{2}+\mathrm{Na}^{+} \rightarrow(\mathrm{Fe}, \mathrm{Pb}) \mathrm{SO}_{4(\mathrm{~s})}$
$+\mathrm{NaCl}_{(\mathrm{s})}+\mathrm{H}^{+}$

La saturación de halita observada en las inclusiones fluidas permite sugerir que el Cu pudo ser transportado en forma de complejos clorurados. Si éste fue el caso, la precipitación de las fases sulfuradas puede ser interpretada, por ejemplo, en base a las ecuaciones (2) y (3) (Crerar y Barnes, 1976; Liu y McPhail, 2005):

(2) $(\mathrm{Fe}) \mathrm{Cl}_{2 \text { (ac) }}+2 \mathrm{H}_{2} \mathrm{~S}_{\text {(ac) }} \rightarrow \mathrm{FeS}_{2(\mathrm{~s})}+2 \mathrm{Cl}^{-}+4 \mathrm{H}^{+}$

(3) $\mathrm{CuCl}_{2(\mathrm{ac})}^{-}+\mathrm{H}_{2} \mathrm{O}+\mathrm{FeS}_{2(\mathrm{~s})} \rightarrow \mathrm{Cl}^{-}+1 / 4 \mathrm{O}_{2}+\mathrm{H}^{+}+\mathrm{CuFeS}_{2(\mathrm{~s})}$

Esta interpretación es consistente con las observaciones texturales que indican que la calcopirita precipitó, con posterioridad a pirita y pirrotina.
Los valores de $\delta^{34} S$ calculados para el fluido son semejantes a los valores obtenidos de pirrotina y pirita (levemente negativos, Tabla 11), reflejan equilibrio isotópico entre el fluido y los sulfuros, compatibles con condiciones de un fluido reductor enriquecido en $\mathrm{H}_{2} \mathrm{~S}$. La calcopirita, no obstante, muestra un $\delta^{34} \mathrm{~S}$ ligeramente positivo (Tabla 11), probablemente debido a un cambio en la $\mathrm{fO}_{2}(\mathrm{y} / \mathrm{o} \mathrm{pH})$, que podría haber modificado ligeramente la relación $\mathrm{H}_{2} \mathrm{~S} \mathrm{SO}_{4}{ }^{2-}$; este cambio del estado de oxidación se puede atribuir a la pérdida de $\mathrm{H}$ o a la oxidación de $\mathrm{H}_{2} \mathrm{~S}$ durante el evento de ebullición (Ohmoto, 1972; Drummond y Ohmoto, 1985; Taylor, 1987). Los valores de $\delta^{34} \mathrm{~S}$ de los sulfuros de la fase de relleno, permiten inferir un origen magmático para el azufre.

Las razones $\mathrm{Fe}^{2+} /\left(\mathrm{Fe}^{+2}+\mathrm{Fe}^{3+}\right)$ en piroxenos y granates $(0,72-0,91$ y $0,41-0,64$, respectivamente) del skarn, las altas proporciones molares de granates subcálcicos del skarn, la existencia de fases sulfuradas como cristales hijos y las altas relaciones $\mathrm{H}_{2} \mathrm{~S}_{\mathrm{SO}_{4}}{ }^{2-}$ estimadas para el fluido vinculado a la precipitación de sulfuros, sugieren la evolución del sistema bajo condiciones dominantemente reductoras, hecho consistente con la presencia de pirrotina entre los sulfuros de las vetas y vetillas.

\subsection{Origen de los fluidos mineralizantes}

Las evidencias de terreno sugieren que los fluidos responsables del metasomatismo que originó los skarns y depositó los sulfuros circularon a través de 


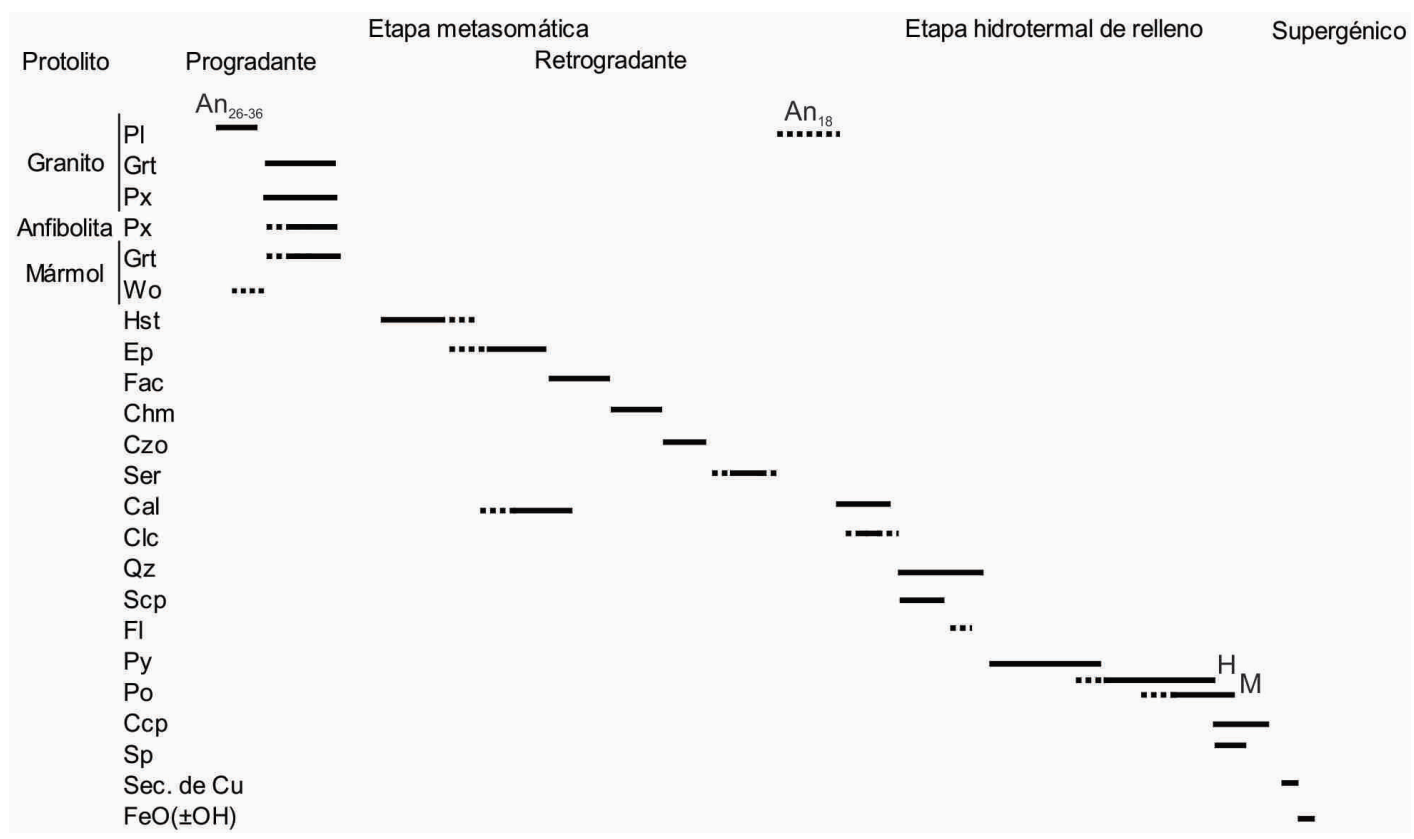

FIG. 8. Secuencia paragenética inferida. Pl: plagioclasa; Grt: granate; Px: piroxeno; Wo: wollastonita; Hst: hastingsita; Ep: epidoto; Czo: clinozoisita; Fac: ferroactinolita; Chm: chamosita; Ser: sericita; Cal: calcita; Clc: clinocloro; Qz: cuarzo; Scp: escapolita; Fl: fluorita; Py: pirita; Po: pirrotina; Ccp: calcopirita; Sp: esfalerita; Sec. de Cu: Fases secundarias de cobre; $\mathbf{F e O}( \pm \mathbf{O H})$ : óxi-hidróxidos de hierro; H: pirrotina hexagonal; M: pirrotina monoclínica; An: proporciones molares de anortita.

contactos litológicos y/o fallas/fracturas. Sin embargo, el origen de estos es difícil de dilucidar; no existen evidencias que permitan establecer un vínculo genético entre los cuerpos intrusivos deformados aflorantes en el área de estudio y los fluidos metasomáticos que dieron origen a los diversos cuerpos de skarn y mineralización. Éstos podrían derivar de una fuente ígnea profunda vinculada temporalmente a intrusivos cámbricos post-deformacionales (post-D3), o bien fueron liberados durante el evento metamórfico de alto grado y la migmatización (M2) que afectó, a escala regional, a las rocas que afloran en el área de estudio (e.g., Martino y Guereschi, 2016). Las inclusiones fluidas no aportan información significativa a favor de una u otra fuente; en ellas no se han identificado fases gaseosas (e.g., $\mathrm{CO}_{2}, \mathrm{~N}_{2} \mathrm{CH}_{4}$ ) que tipifiquen un origen metamórfico; por otro lado, las salinidades intermedias podrían sugerir una fuente ígnea.

La circulación de fluidos mineralizantes y su depositación en vetas y vetillas pseudo-concordantes con la skarnificación habría sido favorable en superficies dilatacionales a partir de esfuerzos extensivos opuestos a la componente regional compresiva (Martino,
2018, comunicación personal). Este mecanismo de relajación estructural o descompresión localizada de menor escala, podría haber sido el responsable del proceso de ebullición.

La presencia de sulfuros de cobre, hierro y cinc en los skarns de Malagueño, podría estar relacionada a un enriquecimiento primario de $\mathrm{Cu}-\mathrm{Fe}$ en las litologías sedimentarias pre-metamórficas y en los diques gabro-dioríticos que las intruyen (940 ppm en para-anfibolitas y 290-230 ppm en diques gabrodioríticos); ambas litologías evidencian la presencia de sulfuros diseminados de cristalización previa al proceso de skarnificación y redistribución hidrotermal y podrían ser consideradas como potenciales fuentes de metales. El evento de skarnificación de estos protolitos sería el mecanismo responsable de la puesta en solución de los metales y el azufre; la disolución y/o desulfuración de sulfuros magmáticos primarios presentes en las rocas del basamento es un hecho conocido (e.g., Kerrick, 1987). Sin embargo, debido al volumen reducido de los diques gabro-dioríticos y anfibolitas, no se puede afirmar que estas rocas sean la única fuente de aporte de metales. 


\subsection{Edad del evento generador de skarn}

Las rocas que constituyen el basamento proterozoico superior-cámbrico en la Sierra Chica, del cual forma parte el área de estudio, han sido afectadas por la orogénesis Pampeana (Gordillo y Lencinas, 1979; Dalla Salda, 1984; Pankhurst y Rapela, 1998, entre otros) y presentan metamorfismo de alto grado y migmatización. Los afloramientos de skarn en Malagueño son concordantes con la fábrica tectónica regional. Ésta caracteriza al evento de deformación D3, post-metamórfico regional M2-D2 que afectó el basamento de las Sierras de Córdoba (metamorfismo y anatexis). Ambos eventos (M2-D2 y D3) se circunscriben al orógeno Pampeano y están temporalmente restringidos al rango $\sim 548-510 \mathrm{Ma}$ (Guereschi y Martino, 2014; Martino y Guereschi, 2014), razón por la cual el evento que generó el skarn y depositó los sulfuros estaría restringido a la etapa póstuma de la orogénesis Pampeana.

La ausencia de minerales ricos en F (e.g., vesuvianita), la escasa ocurrencia de fluorita, la escasez de fluorapatita y el $\mathrm{F}$ no detectable en los granates, descartan para los cuerpos de skarn de Malagueño un origen vinculado al magmatismo Achaliano (Devónico-Carbonífero).

\section{Conclusiones}

La Cantera Centro del yacimiento de mármol de Malagueño (Córdoba, Argentina) presenta litologías vinculadas a un sistema metasomático que dio origen a varios cuerpos de skarn, generados a partir de la infiltración de origen profundo de fluidos canalizados principalmente a lo largo de contactos entre litologías metasedimentarias y metaígneas, entre las que dominan un intrusivo granítico álcali-feldespático, diques gabrodioríticos y tonalíticos, anfibolitas y mármoles. Se han identificado tres tipos de skarn formados a partir de la interacción de fluidos con distintas litologías protolíticas: 1) un skarn de granate-piroxeno ( \pm plagioclasa $\left[\mathrm{An}_{26-38}\right]$ ) desarrollado a partir del reemplazo de granito álcalifeldespático, 2) un skarn de piroxeno generado por reemplazo metasomático de anfibolitas y 3) un skarn de granate (+/-wollastonita) desarrollado a partir del mármol. Sobrepuesta a éstos, se ha desarrollado una asociación retrogradante de epidoto-anfíbol (hastingsita -ferroactinolita)-chamosita-clinozoisita-muscovita (sericita) \pm plagioclasa $\left(\mathrm{An}_{18}\right) \pm$ escapolita \pm fluorita. Los sulfuros presentes en el skarn (pirrotina>pirita calcopirita>>esfalerita) se depositaron en vetas y vetillas asociadas a calcita-clinocloro-cuarzo transgrediendo a las asociaciones progradantes y retrogradantes. Este evento se produce a partir de $\sim 360^{\circ} \mathrm{C}$ y evolucionó con el descenso térmico a partir de la ebullición de un fluido subsaturado en sales cloruradas $(\mathrm{Na}>>\mathrm{K})$, hacia un sistema saturado en $\mathrm{NaCl}$. El sistema de skarn se desarrolló desde la etapa progradante hasta la etapa de relleno con mineralización de sulfuros, bajo condiciones reductoras. Los valores de $\delta^{34} S$ de los sulfuros indican un origen magmático del azufre. El aporte de metales podría derivar de las litologías del encajonante metamórfico, removidos y recristalizados en vetas y vetillas durante la etapa evolutiva final de skarnificación, aunque no puede descartarse por completo la participación de metales aportados por los fluidos de origen magmático o migmático.

Con respecto al origen de los fluidos formadores de los cuerpos de skarn se postulan dos probables orígenes: 1) Vinculados a algún intrusivo cámbrico post-deformacional profundo no aflorante, o 2) Derivados de la migmatización (evento M2) del basamento Neoproterozoico-Cámbrico.

\section{Agradecimientos}

El presente trabajo fue realizado con aportes de la Secretaria de Ciencia y Tecnología de la Universidad Nacional de Córdoba (Res. No.: 313/16 y 113/17) y del CONICET (PIP 11220120100298 CO). Agradecemos a la empresa Holcim Argentina S.A. el acceso y la cordial atención recibida durante las tareas de campaña en la cantera. La Dra. A.B. Guereschi (CONICET-UNC) colaboró en la realización de los análisis químicos por microsonda de electrones. Durante los trabajos de campaña fue valiosa la participación del geólogo F. Álvarez. Los autores están muy agradecidos por los esclarecedores comentarios aportados por el Dr. R.D. Martino sobre el probable vínculo entre fluidos y migmatización dentro del contexto evolutivo dinámico-estructural del basamento de las Sierras de Córdoba y al Dr. J. Sfragulla sobre las manifestaciones cupríferas de la Sierra de Córdoba en su relación con el basamento pampeano. Esta contribución fue notablemente mejorada con los aportes constructivos de los árbitros F. Tornos, F. Henríquez y el detallado trabajo editorial de W. Vivallo.

\section{Referencias}

Angelelli, V. 1984. Yacimientos metalíferos de la República Argentina I. Comisión de Investigaciones Científicas de la Provincia de Buenos Aires: 379 p. Buenos Aires. 
Anzil, P.A.; Guereschi, A.B.; Martino, R.D. 2014. Las rocas ultramáficas de las Sierras de Córdoba. In Geología y recursos naturales de la provincia de Córdoba I. Relatorio del Congreso Geológico Argentino, No. 19 (Martino, R.D.; Guereschi, A.B.; editores). Asociación Geológica Argentina: 129-150. Córdoba.

Argüello, M. 2011. Caracterización físico-mecánica y litológica de las rocas de las canteras de la "Estancia San Nicolás”: Aptitud de la roca como agregado pétreo. Sierra de La Cruz, Malagueño. Córdoba. Memoria de Título (Inédito), Universidad Nacional de Córdoba, Facultad de Ciencias Exactas, Físicas y Naturales: 106 p.

Arnosio, M.; Popridkin, C.; Báez, W.; Bustos, E. 2014. El volcanismo terciario: Complejo Volcánico Pocho. In Geología y recursos naturales de la provincia de Córdoba II. Relatorio del Congreso Geológico Argentino, No. 19 (Martino, R.D.; Guereschi, A.B.; editores). Asociación Geológica Argentina: 623-647. Córdoba.

Astini, R.; Del Papa, C. 2014. Cubierta sedimentaria paleozoica superior. In Geología y recursos naturales de la provincia de Córdoba I. Relatorio del Congreso Geológico Argentino, No. 19 (Martino, R.D; Guereschi, A.B.; editores). Asociación Geológica Argentina: 393-420. Córdoba.

Astini, R.; Oviedo, N. 2014. Cubierta sedimentaria mesozoica. In Geología y recursos naturales de la provincia de Córdoba I. Relatorio del Congreso Geológico Argentino, No. 19 (Martino, R.D; Guereschi, A.B; editores). Asociación Geológica Argentina: 435372. Córdoba.

Astini, R.A.; Tauber, A.A.; Marengo, H.G.; Oviedo, N. 2014. Cubierta cenozoica (Paleógeno-Neógeno). In Geología y recursos naturales de la provincia de Córdoba II. Relatorio del Congreso Geológico Argentino, No. 19 (Martino, R.D.; Guereschi, A.B.; editores). Asociación Geológica Argentina: 539-589. Córdoba.

Bakker, R.J. 2003. Package FLUIDS 1. Computer programs for analysis of fluid inclusion data and for modelling bulk fluid properties. Chemical Geology 194: 3-23.

Battaglia, S. 1999. Applying X-ray geothermometer diffraction to a chlorite. Clays and Clay Minerals 47 (1): 54-63.

Barnes, H. 1979. Solubilities of ore minerals. In Geochemistry of Hydrothermal Ore Deposits. John Wiley and Sons: 404-460. New York.

Becker, U.; Munz, A.W.; Lennie, A.R.; Thornton, G.; Vaughan, D.J. 1997. The atomic and electronic structure of the (001) surface of monoclinic pyrrhotite $\left(\mathrm{Fe}_{7} \mathrm{~S}_{8}\right)$ as studied using STM, LEED and quantum mechanical calculations. Surface Science 389 (1-3): 66-87.

Bodnar, R.J.; Vityk, M.O. 1994. Interpretation for microthermometry data for $\mathrm{NaCl}-\mathrm{H}_{2} \mathrm{O}$ fluid inclusión. In Fluid Inclusions in Minerals, Methods and Applications (De Vivo, E.; Frezzotti, M.L.; editors). Virginia Tech: 117-130. Blacksburg.

Bonalumi, A.A.; Sfragulla, J.; Martino, R.; Zarco, J.; Carignano, C.; Baldo, E.A.; Kraemer, P.; Escayola, M.; Tauber, A.; Cabanillas, A.; Juri, E.; Torres, B. 1999. Hoja geológica 3166-IV Villa Dolores. Provincias de Córdoba y La Rioja. Instituto de Geología y Recursos Minerales. Servicio Geológico Minero Argentino. Programa Nacional de Cartas Geológicas 1:250.000. 122 p.

Brodtkorb, M.K de; Hillar, N.; Ametrano, S. 1981. Consideraciones genéticas en los bancos de cobre presentes en las canteras de caliza de la "Cañada de Álvarez”, provincia de Córdoba. In Congreso Geológico Argentino, No. 8, Actas II: 851-861. San Luis.

Brodtkorb, M.K. de; Coniglio, J.; Miró, R. 2014. Yacimientos metalíferos y metalogenia. In Geología y recursos naturales de la provincia de Córdoba II. Relatorio del Congreso Geológico Argentino, No. 19 (Martino, R.D.; Guereschi, A.B.; editores). Asociación Geológica Argentina: 1025-1075. Córdoba.

Cathelineau, M.; Nieva, D. 1985. A chlorite solid solution geothermometer. The Los Azules (Mexico) geothermal system. Contributions to Mineralogy and Petrology 91: 235-244.

Cathelineau, M. 1988. Cation site occupancy in chlorites and illites as a function of temperature. Clays and Clay Minerals 23: 471-485.

Cingolani, C.; Varela, R. 1975. Geocronología RubidioEstroncio de rocas ígneas y metamórficas de la Sierra Chica y Grande de Córdoba. In Congreso IberoAmericano de Geología Económica, No. 2, Actas 1: 9-35. Buenos Aires.

Colombo, F.; Lira, R.; Ripley, E.M.; González Del Tánago, J. 2011. Geology, mineralogy and possible origin of the copper mineralization in marble near Saldán, Córdoba (Argentina). Journal of Geosciences 56: 299-316.

Colombo, F.; Lira, R.; Viñas, N. 2013. Kinoíta en el skarn de la Cantera Sur (Malagueño), Córdoba. In Congreso de Mineralogía y Metalogenia, No. 11, Actas 1: 3944. San Juan.

Craig, J.R.; Scott, S.D. 1982. Sulfide phase equilibria. In Sulfide Mineralogy (Ribbe, P.H.; editor). Reviews in Mineralogy 1: CS1-110.

Crerar, D.A.; Barnes, H.L. 1976. Ore solution chemistry V. Solubilities of chalcopyrite and chalcocite assemblages 
in hydrothermal solution at 200 to $300{ }^{\circ} \mathrm{C}$. Economic Geology 71: 772-794.

Dahlquist, J.A.; Alasino, P.H.; Bello, C. 2013. Devonian F-rich peraluminous A-type magmatism in the protoAndean foreland (Sierras Pampeanas, Argentina): geochemical constraints and petrogenesis from the western-central región of the Achala batholith. Mineralogy and Petrology 108: 391-417.

Dalla Salda, L.H. 1984. La estructura íntima de las Sierras de Córdoba. Revista de la Asociación Geológica Argentina 39 (1-2): 38-52.

Daziano, C.O. 2004. Las anfibolitas de la Sierra Chica de Córdoba. Universidad Nacional de Córdoba: 130 p. Córdoba.

Demange, M.; Álvarez, J.O.; López, L.; Zarco, J.J. 1996. The Achala Batholith (Córdoba, Argentina): a composite intrusion made of five independent magmatic suites. Magmatic evolution and deuteric alteration. Journal of South American Earth Sciences 9 (1-2): 11-25.

De Caritat, P.; Hutcheon, I.; Walshe, J.L. 1993. Chlorite Geothermometry: A Review. Clays and Clay Minerals 41 (2): 219-239.

D’Eramo, F.J.; Pinotti, L.P.; Bonalumi, A.; Sfragulla, J.; Demartis, M.; Coniglio, J.; Baldo, E.G. 2014. El magmatismo ordovícico de las Sierras Pampeanas de Córdoba. In Geología y recursos naturales de la provincia de Córdoba II. Relatorio del Congreso Geológico Argentino, No. 19 (Martino, R.D.; Guereschi, A.B.; editores). Asociación Geológica Argentina: 233-254. Córdoba.

Dorais, M.J.; Lira, R.; Chen, Y.; Tingey, D. 1997. Origin of biotite-apatite- rich enclaves, Achala batholith, Argentina. Contributions to Mineralogy and Petrology 130: 31-46.

Droop, G.T.R. 1987. A general equation for estimating $\mathrm{Fe}^{3+}$ concentrations in ferromagnesian silicates and oxides from microprobe analyses, using stoichiometric criteria. Mineralogical Magazine 51: 431-435.

Drummond, S.E.; Ohmoto, H. 1985. Chemical evolution and mineral deposition in boiling hydrothermal systems. Economic Geology 80: 126-147.

Einaudi, M.T. 1971. The intermediate product of pyrrhotite alteration. American Mineralogist 56: 1297-1302.

Escayola, M.P.; Kraemer, P.E. 2003. Significado geotectónico de las suturas de Sierras Pampeanas Orientales en la Faja Orogénica Córdoba: posible correlación con orógenos brasilianos. Revista Brasileira de Geociências 33: 69-76.

Escayola, M.P.; Pimentel, M.M.; Armstrong, R. 2007. Neoproterozoic backarc basin: Sensitive high-resolution ion microprobe $\mathrm{U}-\mathrm{Pb}$ and $\mathrm{Sm}-\mathrm{Nd}$ isotopic evidence from the Eastern Pampean Ranges, Argentina. Geology 35 (6): 495-498.

Franchini, M.; Lira, R.; Sfragulla, J. 1998a. El skarn Cañada del Puerto ( $31^{\circ} 25^{\prime}$ LS; $64^{\circ} 54^{\prime}$ LO), provincia de Córdoba: otro ejemplo de metasomatismo caracterizado por fluidos ricos en agua, hidrógeno y flúor. Revista de la Asociación Geológica Argentina 53: 247-260.

Franchini, M.; Lira, R.; Sfragulla, J. 1998b. Zonación mineralógica y evolución de los fluidos en el skarn Copina, provincia de Córdoba (64³9’ O; 31³0’ S). Revista de la Asociación Geológica Argentina 53: 197-211.

Franchini, M.; Lira, R.; Sfragulla, J. 1999. Los skarns San Marcos Sierra y La Falda: geología, mineralogía y composición de los fluidos hidrotermales. Comparación con otros skarns de las Sierras Pampeanas Orientales de Córdoba. Revista de la Asociación Geológica Argentina 54: 420-435.

Frimmel, H.E. 1997. Chlorite thermometry in the Witwatersrand Basin: constraints on the Paleoproterozoic Geotherm in the Kaapvaal Craton, South Africa. The Journal of Geology 105: 601-615.

Gaido, M.F.; Miró, R.C. 1998. Caracterización petrográfica y geoquímica del Gabro Cañada del Puerto (San Alberto), Córdoba. In Congreso Latinoamericano de Geología, No. 10 y Congreso Nacional de Geología Económica, No. 6, Actas 2: 281-288. Buenos Aires.

Galliski, M.A.; Sfragulla, J. 2014. Las pegmatitas graníticas de las Sierras de Córdoba. In Geología y recursos naturales de la provincia de Córdoba II. Relatorio del Congreso Geológico Argentino, No. 19 (Martino, R.D.; Guereschi, A.B.; editores). Asociación Geológica Argentina: 365-388. Córdoba.

Gordillo, C.E. 1965. Variaciones químico-mineralógicas en el contacto de una aplita con mármol dolomítico. Boletín Academia Nacional de Ciencias 44 (1): 53-60.

Gordillo, C.E.; Rossi, J.N. 1968. Escapolita de la cantera El Pozo, Alta Gracia. In Jornadas Geológicas Argentinas, No. 3, Actas 3: 1-11. Chubut.

Gordillo, C.E.; Lencinas, A.N. 1979. Sierras Pampeanas de Córdoba y San Luis. In Segundo Simposio de Geología Regional Argentina I. Academia Nacional de Ciencias: 577-650. Córdoba.

Guereschi, A.B.; Martino, R.D. 2014. Las migmatitas de las Sierras de Córdoba. In Geología y recursos naturales de la provincia de Córdoba II. Relatorio del Congreso Geológico Argentino, No. 19 (Martino, R.D.; Guereschi, A.B.; editores). Asociación Geológica Argentina: 67-94. Córdoba. 
Hawthorne, F.C.; Oberti, R.; Harlow, G.E.; Maresch, W.V.; Martin, R.F.; Schumacher, J.C.; Welch, M.D. 2012. IMA report nomenclature of the amphibole supergroup. American Mineralogist 97: 2031-2048.

Jiang, W.T.; Peacor, D.R.; Buseck, P.R. 1994. Chlorite geothermometry-contamination and apparent octahedral vacancies. Clays and Clay Minerals 42: 593-605.

Jowett, E.C. 1991. Fitting iron and magnesium into the hydrothermal chlorite geothermometer. GAC/MAC/ SEG Joint Annual Meeting, Program with Abstracts 16: A62. Toronto.

Kay, S.M.; Gordillo, C.E. 1994. Pocho volcanic rocks and the melting of depleted continental lithosphere above a shallowly dipping subduction zone in the central Andes. Contributions to Mineralogy and Petrology 117: 25-44.

Kerrich, R. 1987. The stable isotope geochemistry of $\mathrm{Au}-\mathrm{Ag}$ vein deposits in metamorphic rocks. In Stable Isotope Geochemistry of Low Temperature Processes (Kyser, T.K.; editor). Mineralogical Association of Canada 13: 287-336. Saskatoon.

Kissin, S.A.; Scott, S.D. 1982. Phase relation involving pyrrhotite below $350{ }^{\circ} \mathrm{C}$. Economic Geology 77: 1739-1754.

Kraemer, P.E.; Escayola, M.P.; Martino, R.D. 1995. Hipótesis sobre la evolución tectónica neoproterozoica de las Sierras Pampeanas de Córdoba (3040’-3240’), Argentina. Revista de la Asociación Geológica Argentina 50 (1-4): 47-59.

Kwak, T.A.P. 1986. Fluid inclusions in skarns (carbonate replacement deposits). Journal of Metamorphic Geology 4: 363-384.

Lagorio, S.L; Vizán, H.; Geuna, S.E. 2014. El volcanismo alcalino cretácico. In Geología y recursos naturales de la provincia de Córdoba I. Relatorio del Congreso Geológico Argentino, No. 19 (Martino, R.D; Guereschi, A.B; editores). Asociación Geológica Argentina: 473511. Córdoba.

Lianxing, G.; Vokes, F.M. 1996. Intergrowths of hexagonal and monoclinic pyrrhotites in some sulphide ores from Norway. Mineralogical Magazine 60: 303-316.

Lira, R.; Kirschbaum, A.M. 1990. Geochemical evolution of granites from the Achala batholith of the Sierras Pampeanas, Argentina. In Plutonism from Antarctica to Alaska (Kay, S.M..; Rapela, C.W.; editors). Geological Society of America, Special Paper 241: 67-76.

Lira, R.; Millone, H.A.; Kirschbaum, A.M.; Moreno, R.S. 1997. Calc-Alkaline Arc Granitoid Activity in the Sierra Norte-Ambargasta Ranges, Central Argentina.
Journal of South American Earth Sciences 10 (2): 157-177.

Lira, R.; Gay, H.D. 1999. Clinozoisita rosada en las Sierras de Córdoba. Revista de la Asociación Geológica Argentina 54 (2): 109-122.

Lira, R.; Sfragulla, J. 2014. El magmatismo devónicocarbonífero: el batolito de Achala y plutones menores al norte del cerro Champaquí. In Geología y recursos naturales de la provincia de Córdoba II. Relatorio del Congreso Geológico Argentino, No. 19 (Martino, R.D.; Guereschi, A.B.; editores). Asociación Geológica Argentina: 293-347. Córdoba.

Liu, W.; McPhail, D.C. 2005. Thermodynamic properties of copper chloride complexes and copper transport in magmatic-hydrothermal solutions. Chemical Geology 221: 21-39.

Lucero Michaut, H.N.; Daziano, C.O. 1984. Un gran stock metagábrico preplutónico y su cortejo de gabros metamórficos asociados, Cañada del Puerto, Sierras de Córdoba. In Congreso Geológico Argentino, No. 9, Actas II: 231-242. San Carlos de Bariloche.

Martino, R.D.; Guereschi, A.B.; Anzil, P.A. 2010. Metamorphic and tectonic evolution at 31 ${ }^{\circ} 36^{\prime} \mathrm{S}$ across a deep crustal zone from the Sierra Chica of Córdoba, Sierras Pampeanas, Argentina. Journal of South American Earth Sciences 30: 12-28.

Martino, R.D.; Guereschi, A.B. 2014. La estructura neoproterozoica-paleozoica inferior del complejo metamórfico de las Sierras de Córdoba. In Geología y recursos naturales de la provincia de Córdoba I. Relatorio del Congreso Geológico Argentino, No. 19 (Martino, R.D.; Guereschi, A.B.; editores). Asociación Geológica Argentina: 95-128. Córdoba.

Martino, R.D.; Guereschi, A.B. 2016. Metamorfismo, deformación y fluidos: ejemplos en el Macizo Migmático San Carlos, Sierras Pampeanas de Córdoba. In Reunión sobre Fluidos y Deformación, No. 1, Resúmenes: 1920. Buenos Aires.

Miró, R.C. 1999. El basamento precámbrico-paleozoico inferior de las Sierras Pampeanas, Famatina, Cordillera Oriental y Puna (Introducción). In Geología Argentina (Caminos, R.; editor). Instituto de Geología y Recursos Minerales Servicio Geológico Minero Argentino, Anales 29 (6): 133-135. Buenos Aires.

Mutti, D.; Di Marco, A. 1999. Yacimientos de cobre-hierro y plomo-cinc relacionados a volcanismo submarino, Córdoba. In Recursos Minerales de la República Argentina (Zappettini, E.O.; editor). Instituto de Geología y Recursos Minerales Servicio Geológico Minero Argentino, Anales 35: 307-325. Buenos Aires. 
Ohmoto, H. 1972. Systematics of sulfur and carbon isotopes in hydrothermal ore deposits. Economic Geology 67: 551-578.

Ohmoto, H.; Rye, R.O. 1979. Isotopes of Sulfur and Carbon. In Geochemistry of Hydrothermal Ore Deposits (Barnes, H.; editor). John Wiley and Sons: 509-567. New York.

O’Leary, M.S.; Franchini, M.B.; Lira, R.; Dorais, M.J. 2002. Skarn asociado a un lamprófiro calcoalcalino, Sierra Norte, Córdoba, Argentina. In Congreso Geológico Argentino, No. 15, Actas I: 412-415. El Calafate, Santa Cruz.

Olsacher, J. 1938. Los minerales de las Sierras de Córdoba. Imprenta de la Universidad Nacional de Córdoba: 70 p. Argentina.

Pankhurst, R.J.; Rapela, C.W. 1998. The proto-andean margin of gondwana: an introduction. In The ProtoAndean Margin of Gondwana (Pankhurst, R.J.; Rapela, C.W.; editores). Geological Society, Special Publications 142: 1-9.

Pastore, F. 1932. Hoja 20i del Mapa Geológico de la Argentina, región oriental y media de la Sierra de Córdoba. Dirección Nacional de Geología y Minería, Boletín 36: 1-67.

Rapela, C.W.; Toselli, A.; Heaman, L.; Saavedra, J. 1990. Granite plutonism of the Sierras Pampeanas; An inner cordilleran Paleozoic arc in the southern Andes. Geological Society of America, Special Paper 241: 77-90.

Roedder, E. 1984. Fluid Inclusions. Mineralogical Society of America. Reviews in Mineralogy 12: 644 p. USA.

Rose, A.W.; Burt, D.M. 1979. Hydrothermal Alteration. In Geochemistry of Hydrothermal Ore Deposits (Barnes, H.; editor). John Wiley and Sons: 173-235. New York.

Rye, R.O.; Ohmoto, H. 1974. Sulfur and carbon isotopes and ore genesis: A review. Economic Geology 69: 826-842.
Sakai, H. 1968. Isotopic properties of sulfur compounds in hydrothermal processes. Geochemical Journal 2: 29-49.

Shepherd, T.; Rankin, A.H.; Alderton, D.H.M. 1985. A practical guide to fluid inclusions studies. Blackie: 235 p. Glasgow.

Sfragulla, J.; Jerez, D.; Bonalumi, A. 1999. Mármoles y otras rocas carbonáticas de Córdoba. In Recursos Minerales de la República Argentina (Zappettini, E.O.; editor). Instituto de Geología y Recursos Minerales Servicio Geológico Minero Argentino, Anales 35: 271-295. Buenos Aires.

Streckeisen, A. 1976. To each plutonic rock its proper name. Earth Sciences Reviews 12: 1-33.

Taylor, B.E. 1987. Stable isotope geochemistry of ore. forming fluids. In Stable Isotope Geochemistry of Low Temperature Processes (Kyser, T.K.; editor). Mineralogical Association of Canada, 13: 337-418. Saskatoon.

Tibaldi, A.M.; Demichelis, A.H.; Fagiano, M.R.; Otamendi, J.E.; Rabbia, O. 2014. Las rocas máficas del Paleozoico Inferior de las Sierras de Córdoba. In Geología y recursos naturales de la provincia de Córdoba I. Relatorio del Congreso Geológico Argentino, No. 19 (Martino, R.D.; Guereschi, A.B.; editores). Asociación Geológica Argentina: 151-167. Córdoba.

Valdez, M.A. 1984. Cartografía geológica y estudio petro-mineralógico del Distrito Minero Los Guindos (Departamento Punilla, Provincia de Córdoba). Memoria de Título (Inédito), Universidad Nacional de Córdoba, Facultad de Ciencias Exactas, Físicas y Naturales: 65 p.

Whitney, D.L.; Evans, B.W. 2010. Abbreviations for names of rock-forming minerals. American Mineralogist 95: 185-187.

Wilkinson, J.J. 2001. Fluid inclusions in hydrothermal ore deposits. Lithos 55: 229-272.

Manuscrito recibido: Septiembre 25, 2017; revisado/aceptado: Marzo 8, 2019; disponible en línea: Septiembre 30, 2019. 